\title{
A review of plug-and-perforate, ball-and-seat, and single-entry pinpoint fracturing performance in the unconventional montney reservoir
}

\author{
Benyamin Yadali Jamaloei ${ }^{1}$
}

Received: 17 October 2020 / Accepted: 2 January 2021 / Published online: 13 February 2021

(c) The Author(s) 2021

\begin{abstract}
The Montney tight siltstone reservoir is a multi-stacked play, which covers a total area of $130,000 \mathrm{~km}^{2}$ along the AlbertaBritish Columbia border in Western Canada. Since the late 1990s, different fracturing methods and fluids have been tested in 4000-plus Montney wells to find the optimal fracturing method and fluid. The previous studies reviewing the performance of fracturing methods in Montney do not represent a holistic evaluation of these methods, owing to some limitations, including: (1) using a small sample size, (2) having a limited scope by focusing on a specific aspect of fracturing (method/fluid), (3) relying on data analytics approaches that offer limited subsurface insight, and (4) generating misleading results (e.g., on optimum fracturing method/fluid) through using disparate data that are unstructured and untrustworthy as a result of significant regional variations in true vertical depth (TVD), geological properties, fluid windows, completed lateral length, fracturing method/fluid/date, and drawdown rate management and choke size strategy. The present study eliminates these limitations by rigorously clustering 4000-plus Montney wells based on the TVD, fluid window, completed lateral length, fracturing method/fluid/date, and drawdown rate strategy to isolate the effect of each fracturing method by comparing each well's production to that of its offsets, which use different fracturing methods but possess similar geology, fluid window, and TVD. With similar TVD, fracturing fluid, and completion date, wells completed with pinpoint fracturing method outperform their offsets completed with ball-and-seat and plug-and-perforate (PnP) fracturing methods. However, wells completed with ball-and-seat and PnP methods that outperform their offset pinpoint wells have either: (1) been fractured one to four years earlier than the pinpoint wells and/or (2) used energized oil-based fluid, hybrid fluid, and energized slickwater versus slickwater used in the pinpoint offsets. This suggests that the water-phase trapping is more severe in these pinpoint wells attributable to the use of slickwater. Previous studies often favored one specific fracturing method or fluid without highlighting these complex interplays between the type of fracturing method, fracturing fluid, completion date (regional depletion or well vintage), and the reservoir properties and hydrodynamics.
\end{abstract}

Keywords Fracturing fluid $\cdot$ Water-phase trapping $\cdot$ Pressure depletion $\cdot$ Fluid windows $\cdot$ Disparate dataset

$\begin{array}{ll}\text { Abbreviations } \\ \text { BHA } & \text { Bottom-hole assembly } \\ \text { CT } & \text { Coiled tubing } \\ \text { HW } & \text { Horizontal well } \\ \text { ISIP } & \text { Instantaneous shut-in pressure } \\ \text { PnP } & \text { Plug-and-perforate } \\ \text { TVD } & \text { True vertical depth } \\ \text { UWI } & \text { Unique well identifier }\end{array}$

Benyamin Yadali Jamaloei

Benyamin Yadali Jamaloei
bjamaloei@ncsmultistage.com

1 NCS Multistage Inc., 700-333 7 Ave SW, Calgary, AB T2P 2Z1, Canada

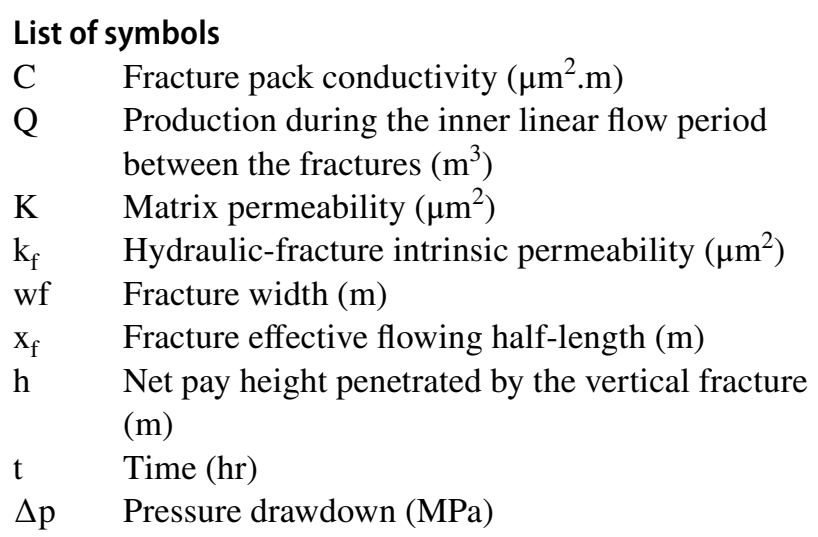

\section{List of symbols}

C Fracture pack conductivity $\left(\mu \mathrm{m}^{2} . \mathrm{m}\right)$

Q Production during the inner linear flow period between the fractures $\left(\mathrm{m}^{3}\right)$

$\mathrm{K} \quad$ Matrix permeability $\left(\mu \mathrm{m}^{2}\right)$

$\mathrm{k}_{\mathrm{f}} \quad$ Hydraulic-fracture intrinsic permeability $\left(\mu \mathrm{m}^{2}\right)$

wf Fracture width (m)

$\mathrm{x}_{\mathrm{f}} \quad$ Fracture effective flowing half-length (m)

$\mathrm{h} \quad$ Net pay height penetrated by the vertical fracture

(m)

Pressure drawdown (MPa) 


\section{Introduction}

The Montney tight siltstone reservoir (Fig. 1) is one of the most prolific unconventional multi-stacked dry and liquid-rich gas plays in North America. It extends $500 \mathrm{~km}$ in length over a total area of $130,000 \mathrm{~km}^{2}$ along the Alberta-British Columbia border. Its total thickness ranges from 100 to $300 \mathrm{~m}$ in the thickest areas. The geology is fairly complex encompassing siltstone with sandstone and dolostone in the southeast to pure siltstone in the northwest of the play. In areas with unconventional development focus, the lithology comprises tight siltstone interbedded with thin shale streaks and variable dolostone. The reservoir matrix permeabilities range from upper $n D$ to mid $\mu D$. From a phase behavior perspective, the play lies in the thermogenic gas window. As of Q4, 2019, 4000plus horizontal wells have been drilled and completed in the Montney. With the current pace of development and assumptions of stacked horizontal development with four wells per section, the drilling inventory in the Montney is estimated to be upward of 150,000 horizontal wells (Reimer 2015).

Some unconventional plays exhibit little sensitivity to water-based fluid-phase trapping. Notable examples include the Barnett shale and Muskwa in the Horn River Basin (Taylor et al. 2010). However, because of the waterphase trapping issues, especially in the lower-quality parts of the Montney, casing deformation in the deeper zones, and fracture hits, the choice of completion technology and fluid can have a significant impact on the well performance, apart from the operational logistics and completion cost variation from one completion type to another. Hence, since the late 2000s, a variety of fracturing techniques (e.g., PnP, PnP with ball, ball-and-seat, and single-entry pinpoint) and fluids (e.g., slickwater, hybrid with linear and/or cross-linked gels, oil-based, energized, foam, and binary foam) have been tested in more than 4000 wells to find the optimum completion type and fluid tailored to variations in reservoir quality, fluid windows, and operational considerations.

Dozens of Montney well-completion-performance reviews have been published (Al-Alwani et al. 2015; Kong et al. 2017; Mohammed et al. 2016; Okouma et al. 2012; Reynolds et al. 2014, 2015; Seifert et al. 2015; Voneiff et al. 2013, 2014; Wang and Chen 2016). However, none of these studies represents a holistic evaluation of the completion performance across the Montney since they either use a small sample size (e.g., Groulx et al. 2017; Mohammed et al. 2016; Okouma et al. 2012; Voneiff et al. 2013, 2014) or have a limited scope by focusing on a specific aspect of either completion type, design, or fluid (e.g., Kong et al. 2017; Reynolds et al. 2014, 2015), or rely on some data analytics approaches that offer limited technical subsurface insight (e.g., Al-Alwani et al. 2015; Mohammed et al. 2016; Okouma et al. 2012; Seifert et al. 2015; Voneiff et al. 2013, 2014; Wang and Chen 2016). Moreover, some of these studies have often generated misleading results (e.g., optimum completion type or fluid) through using disparate datasets that are unstructured and untrustworthy because of significant regional variation in geological properties, fluid windows, completion date, and choke size (drawdown rate) management strategy. This study eliminates these limitations by carefully clustering the 4000-plus Montney wells based on the completed lateral length, completion type/fluid/design/date, operator, and TVD. Moreover, it compares the performance of each well to that of its offsets with varying completion types but similar TVD, geological properties, fluid window, depletion, drawdown strategy, and completion fluid.

\section{Methods}

The production during the inner linear flow between the fractures in hydraulically fractured unconventional wells can be approximated using the following relation:

$Q \propto k^{0.5} x_{f} h t^{0.5} \Delta p$

where $k$ is the matrix permeability $\left(\mu \mathrm{m}^{2}\right), x_{f}$ is the fracture half-length $(\mathrm{m}), h$ is the net pay height penetrated by the vertical fracture (m), $t$ is the time (hr), and $\Delta p$ is the pressure drawdown (MPa).

In order to properly evaluate the well completion performance, one needs to preferably separate the impact of treatment parameters $\left(x_{f}\right)$ versus the reservoir parameters ( $h$ and $k$ ). With the assumption that the fracture vertically penetrates the available net pay, one needs to merely decouple ' $k$ ' from ' $x_{f}$ '. The cumulative experience from the rate transient analysis across the Montney play suggests that the end of the inner linear flow between the hydraulic fractures along a horizontal lateral lies approximately between 18 to 24 months (Reynolds et al. 2015). Also, the permeability of the stimulated reservoir volume is not significantly enhanced in comparison with the matrix permeability in the Montney. Thus, it is safe to assume that the permeability of the stimulated reservoir volume is approximately equal to the matrix permeability. With these provisions, and by comparing a given well only to its offsets with similar matrix permeability, net pay height, and pressure drawdown strategy, the variation in production during the inner linear flow period can be largely attributed to the effective flowing fracture half-length: 

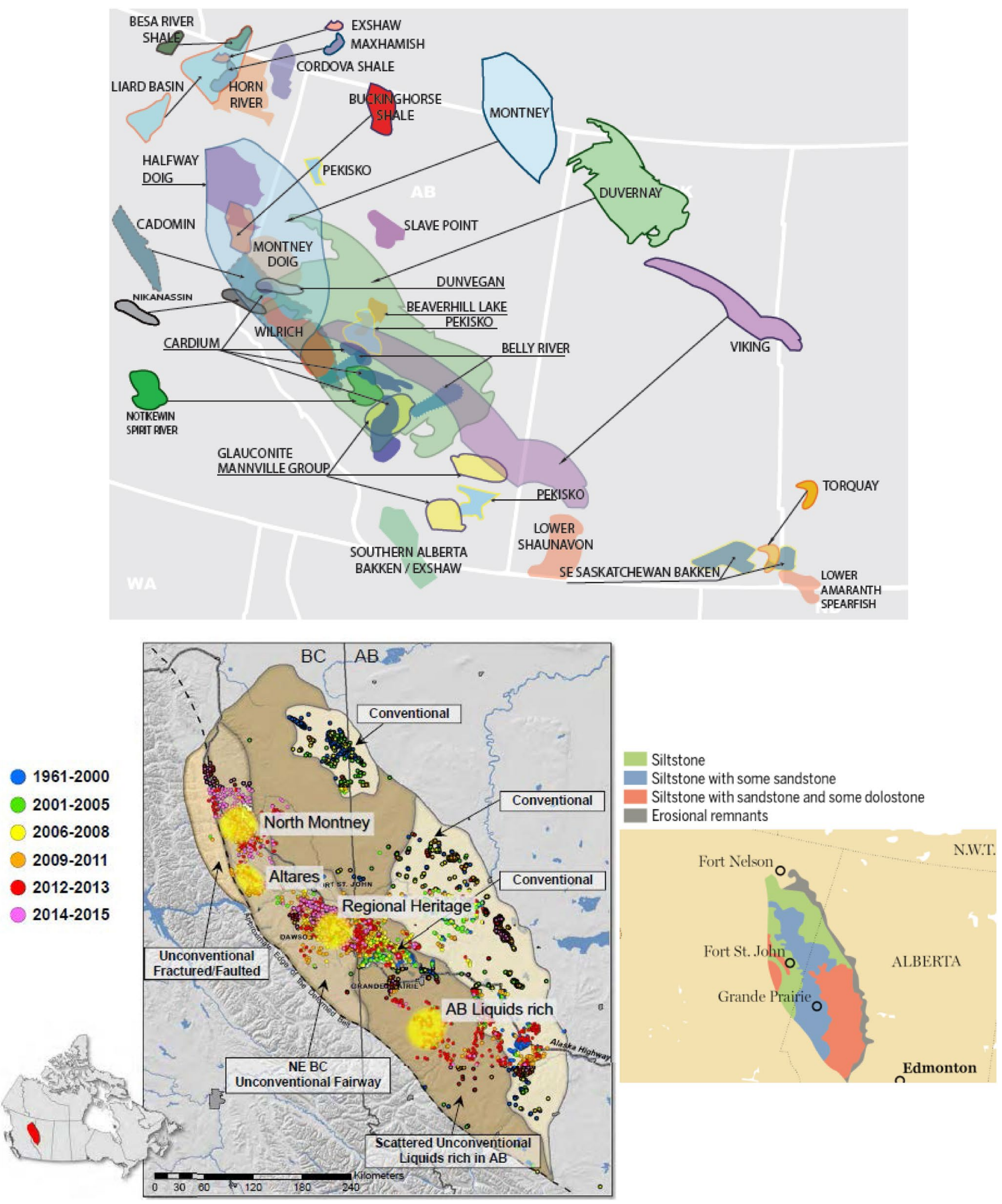

Fig. 1 Top: Montney's position in relation to other western Canada's resource plays ( Source: CAPP); bottom: Montney play evaluation windows, lithological windows, and drilling history since the 1960s (Source: Unconventional Gas Resources) 
$Q \propto k^{0.5} x_{f}$

In order to stay in the inner linear flow period, a reasonable production time is 12 months. This production time is long enough to minimize the gel cleanup effect (which is often three to six months in the Montney) on the production data. Additionally, the 12-month time is not so long to allow the flow transitioning out of the inner linear flow period. Thus, when offset wells with different completion systems (types, design, and fluid) are compared in a large enough sample size, it is reasonable to assume that each stimulation system is equally represented in matrix permeability and net pay thickness, and the production variation from one well to its offset(s) is driven more by the variation in $x_{f}$, a measure of the stimulation effectiveness. Because $x_{f}$ is often selected at a fracture conductivity threshold, $k_{f} w_{f}$, it tacitly includes the effects of stimulation on the hydraulic fracture propped length, aperture, and conductivity (Fig. 2).

With the above considerations, the 12-month production for the pinpoint wells is compared to that of their nearby PnP, PnP (with ball), and ball-and-seat offsets that have similar completion fluid, TVD, and preferably similar completion date. Because reliable completion costs for all of these wells are not available, the normalization of each well's performance by the completed length, proppant tonnage, and fluid volume takes into account some portions of the completion costs (excluding trucking and disposal costs as well as the upfront costs for the downhole completion systems installed in each completion method). In addition, to minimize the effects of the variation in porosity, permeability, and water saturation on the variation in well performance from one completion type to another, the performance of each well (with a different completion method) is only compared with that of its offsets. Finally, to minimize the effect of the variation in the pressure drawdown rate and choke size management

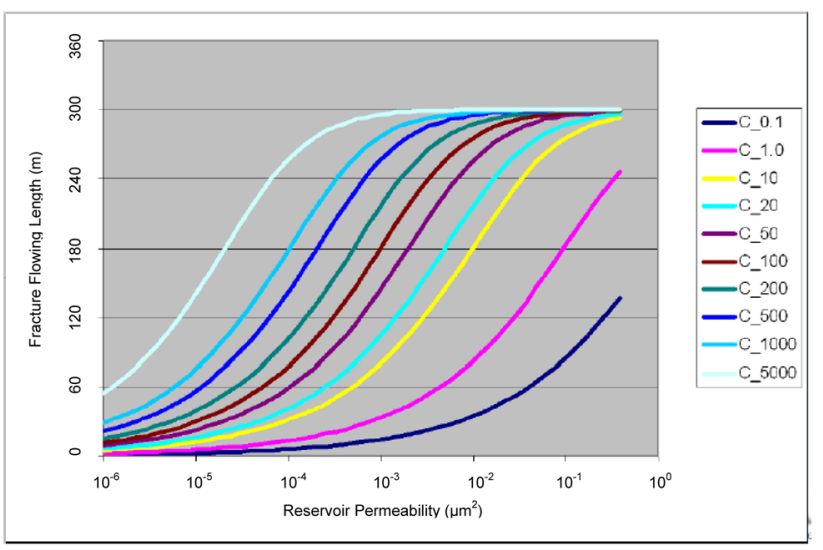

Fig. 2 Maximum cleanup lengths for various pack conductivity, C, values and permeabilities (Barree 2016) on the variation in well performance, the wells are also grouped by operator. For this purpose, six operators (named Operators A to F) are selected in six different areas of the Montney. The cumulative experience in the Montney indicates that the pressure drawdown rate and choke size management strategies which are applied by a given operator to its wells are often consistent.

This clustering technique will demonstrate how proper data structuring in disparate datasets with thousands of wells with significant variations in geological properties, fluid windows, completion type/design/fluid, regional depletion, and drawdown strategy permits a consistent well performance comparison across a play by isolating the impact of any given parameter (e.g., completion types, depletion, fluid, and so forth) that is deemed more crucial to completion design and field development planning.

\section{Results}

Based on various normalized well production indices, the results indicate that the pinpoint wells outperform their balland-seat and $\mathrm{PnP}$ offsets. This comparison is based on similar TVD, completion date, and fluid. Additionally, the balland-seat and PnP wells that outperform their offset pinpoint wells have either been completed one to four years earlier than pinpoint wells and/or used energized oil-based fluid, hybrid fluid, and energized slickwater versus slickwater used in completing the pinpoint offsets. The following detailed comparison for Operators A to F demonstrates the complex interaction between the completion type and design with the fracturing fluid and regional depletion (well vintage). It is noted that because of the large volume of data analyzed, only a portion of the results are presented in this study (for space reasons). The full analysis shall be provided as supplementary data.

\section{Operator A (northern Montney and heritage)}

Figure 3 shows that a total of 110 wells were drilled by Operator A in the Montney (Q4 2019), 34\% of which were completed with the coiled-tubing (CT)-activated singleentry pinpoint fracturing using either jet cuts or sliding sleeve ports. In all of the figures and throughout this study, this completion technology is simply referred to as CT cut/port (packer). The wells completed with CT cut/port (packer) are simply called the pinpoint wells, referring to the single-entry pinpoint fracturing. In addition, $60 \%$ of the wells operated by Operator A in the Montney were completed using the PnP (with ball) method. The objective is to compare the 12-month production for the pinpoint wells versus their nearby PnP (with ball) offsets that have similar completion fluids [slick water (SW) or hybrid that is using 


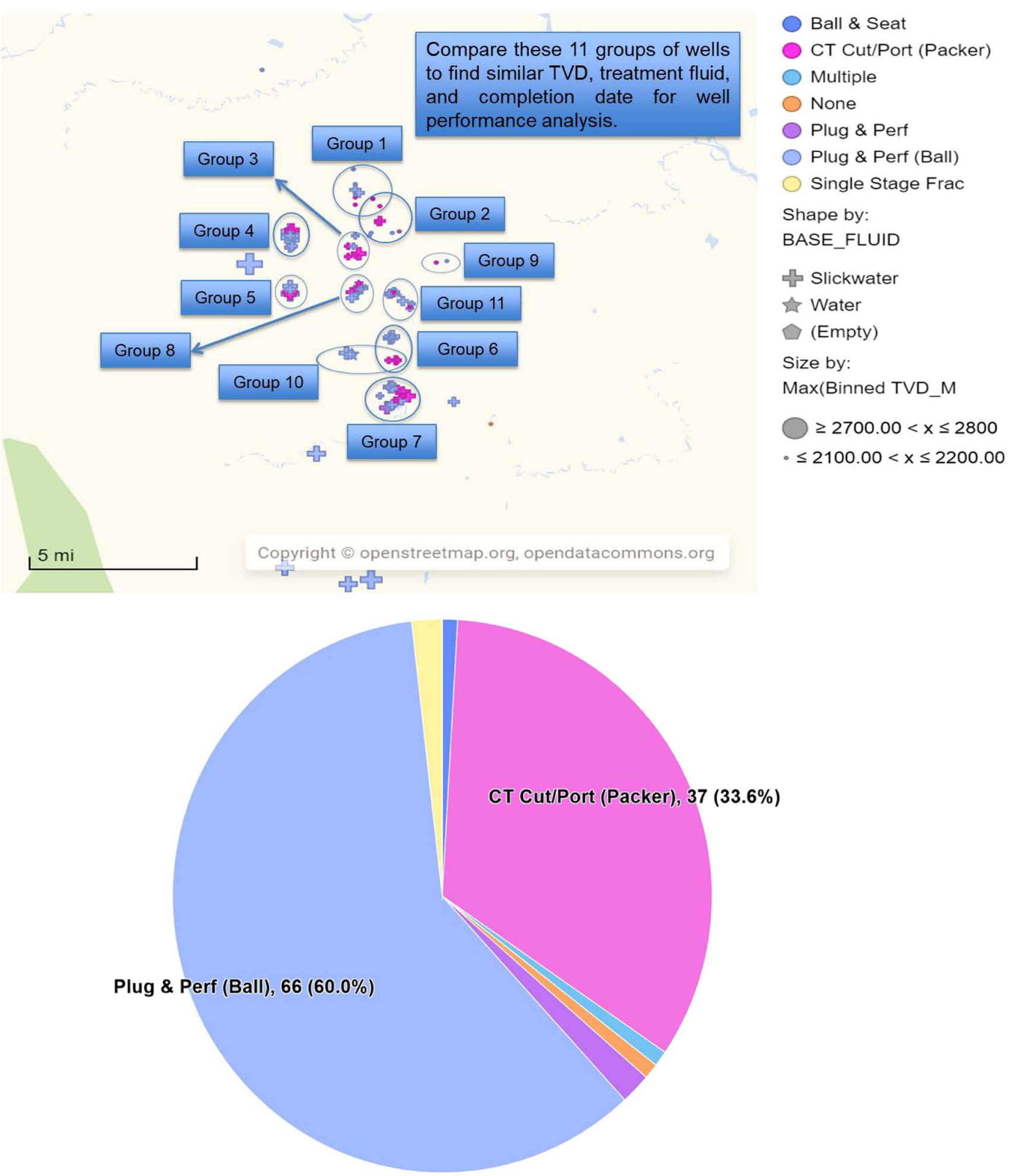

Fig. 3 Top: wells grouping for Company A based on similar TVD, treatment fluid, and completion date to compare the performance of completion types; bottom: well counts and percentage by completion type

both cross-linked/linear gels and slickwater], TVD (range of mostly $2100-2500 \mathrm{~m}$ ), and preferably similar completion date.
Of the total 11 groups of wells, eight groups have enough production data (12-month) to allow a consistent performance comparison between the pinpoint wells 
versus their PnP (with ball) and ball-and-seat offsets. Of the eight groups analyzed, in five groups of wells, both 12 -month production and normalized 12-month production (normalized by completed length, proppant tonnage, and fluid volume) show pinpoint completions outperforming their PnP (with ball) offsets completed by Operator A in Northern Montney and Heritage areas. A sample group (Group 8) is shown in Fig. 4. Generally, the pinpoint wells that outperform their PnP (with ball) offsets have similar TVD (2100-2250 m), completion fluid (either slickwater or hybrid), and completion date (2015-2017).

The PnP (with ball) and ball-and-seat offsets that outperform their offset pinpoint wells in three groups of wells have been completed 2 to 5 years earlier (2011-2015) at a higher local reservoir pressure and/or in sweet spots and
Fig. 4 Comparison of well completion-type performance (normalized by completed lateral length and total fluid/ proppant placed) for Company A (Wells Group 8) based on treatment fluid, completion date, TVD, total fluid pumped, and total proppant placed
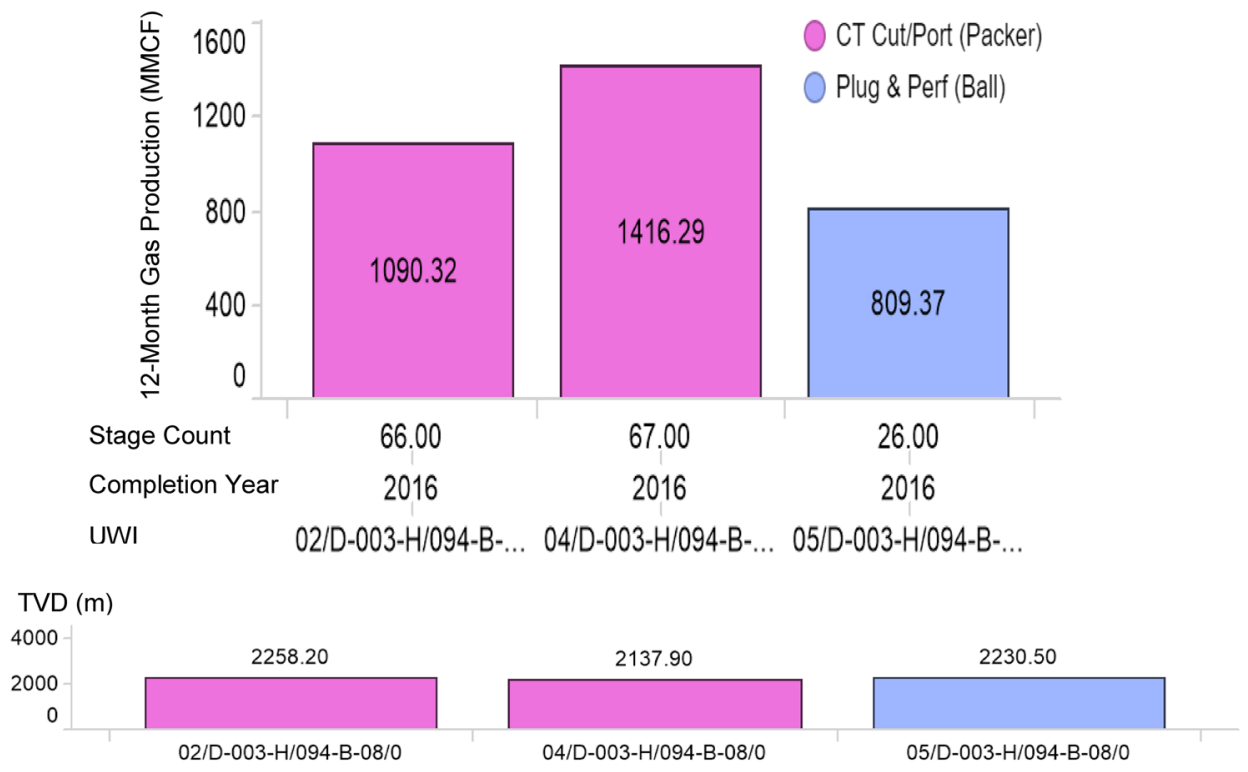

12-Month Gas Production Over Total Proppant Placed (MMCF/t)

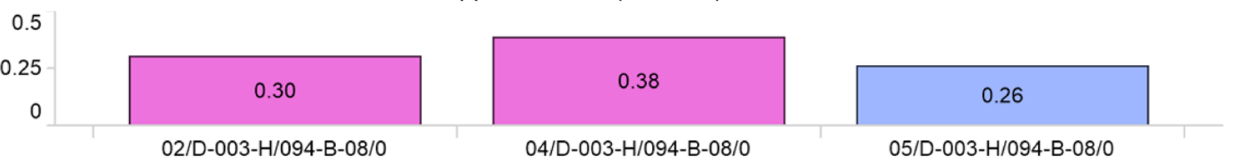

12-Month Gas Production Over Lateral Length $(\mathrm{MBO} / \mathrm{m})$

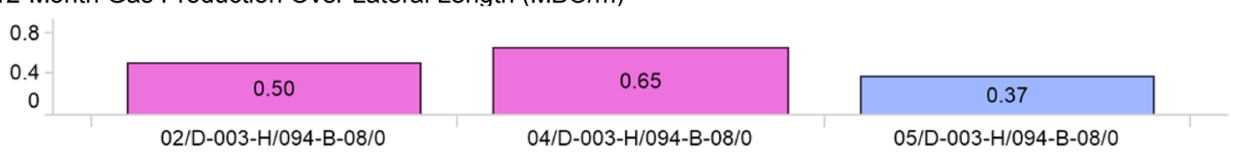

12-Month Gas Production Over Total Fluid Pumped (MMCF $/ \mathrm{m}^{3}$ )
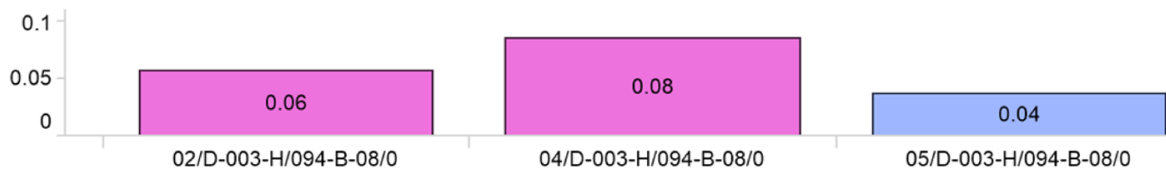

Total Fluid Pumped $\left(\mathrm{m}^{3}\right)$

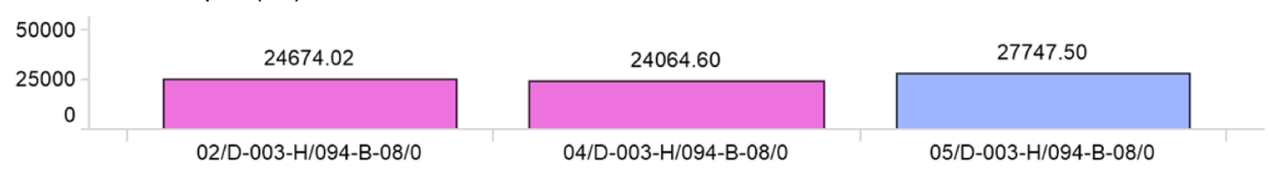

Total Proppant Placed (t)

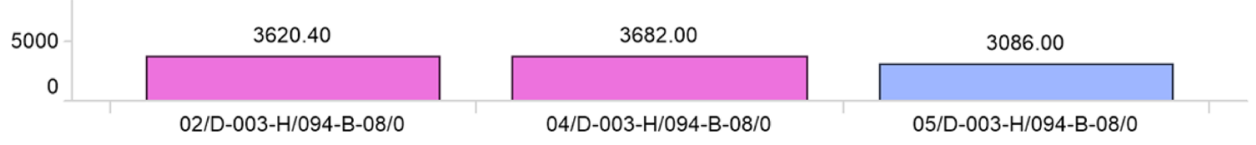


Fig. 5 Comparison of well completion-type performance (normalized by completed lateral length and total fluid/ proppant placed) for Company A (Wells Group 10) based on treatment fluid, completion date, TVD, total fluid pumped, and total proppant placed
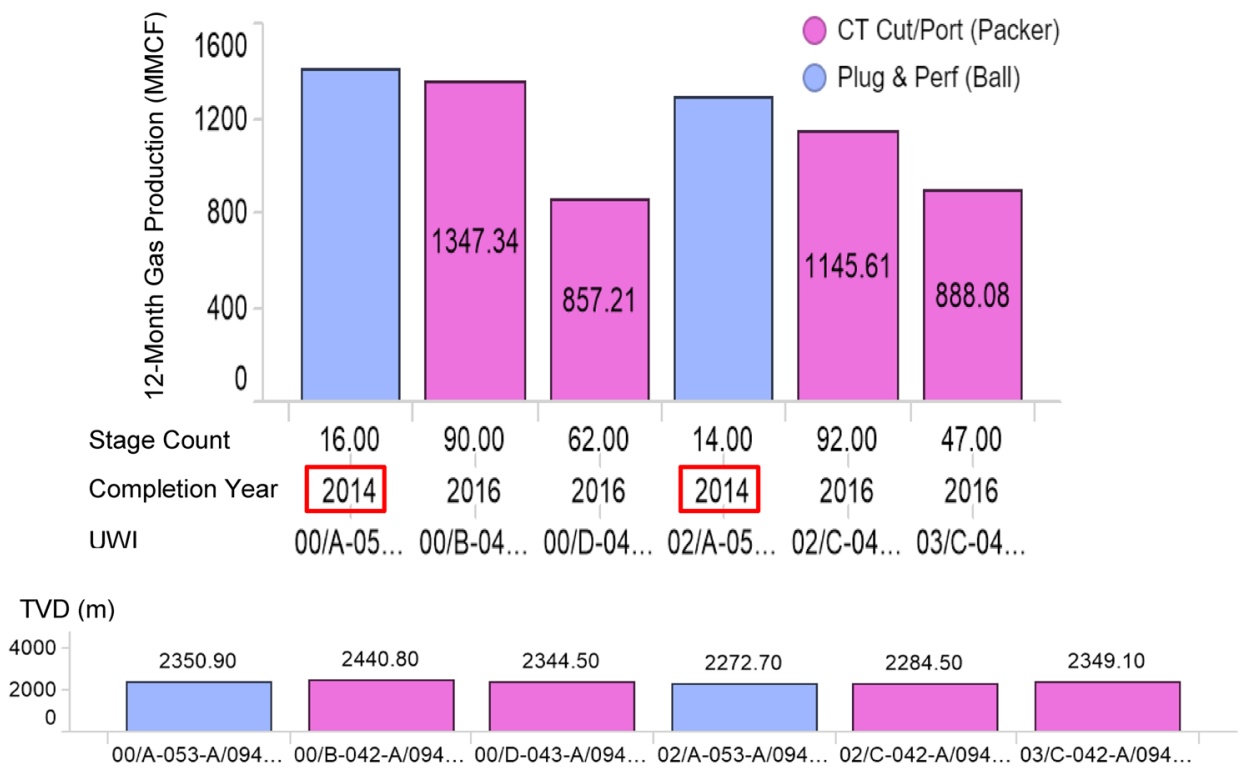

12-Month Gas Production Over Total Proppant Placed (MMCF/t)

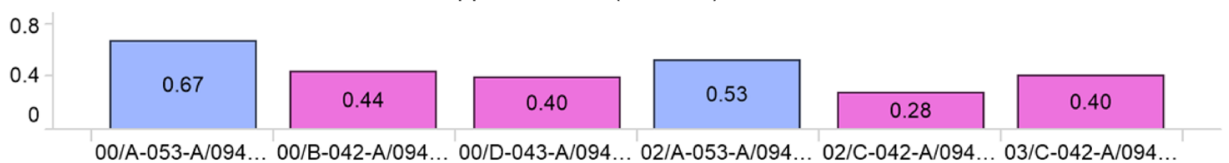

12-Month Gas Production Over Lateral Length (MBO/m)

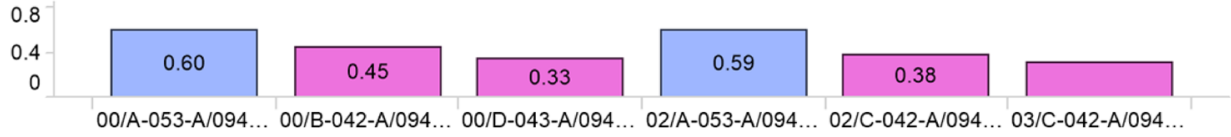

12-Month Gas Production Over Total Fluid Pumped (MMCF/m $\mathrm{m}^{3}$ )

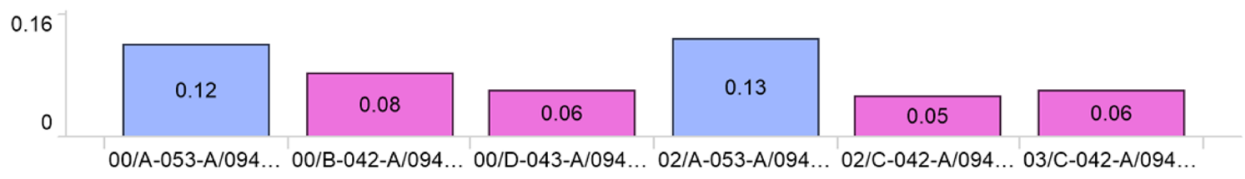

Total Fluid Pumped $\left(\mathrm{m}^{3}\right)$
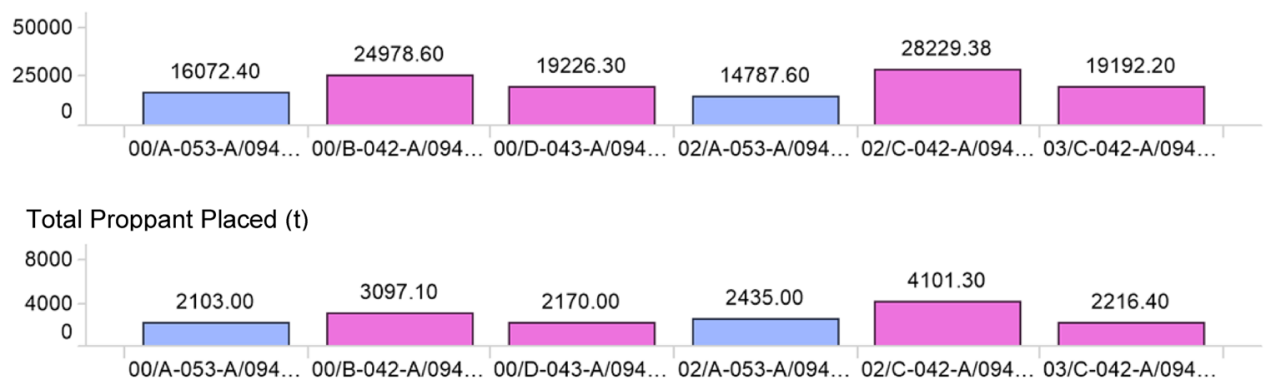

have a TVD of 2300 to $2500 \mathrm{~m}$. A sample group (Group $10)$ is shown in Fig. 5.

\section{Operator B}

Figure 6 shows that of the total of 285 wells completed by Operator B in the Montney (Q4, 2019), 20\% of these wells are pinpoint wells, while $43 \%$ used the ball-and-seat method and 27\% employed either traditional PnP or PnP (with ball) methods. Similar to the analysis performed for the wells completed by Operator A, the focus is to compare the 12-month production for the pinpoint wells versus their nearby $\mathrm{PnP} / \mathrm{PnP}$ (with ball) and ball-and-seat offsets that have similar completion fluids (SW or hybrid), TVD (range of mostly $1500-2800 \mathrm{~m}$ ), and preferably similar completion date. 
Fig. 6 Top: wells grouping for Company B based on similar TVD, treatment fluid, and completion date to compare the performance of completion types; bottom: well counts and percentage by completion type
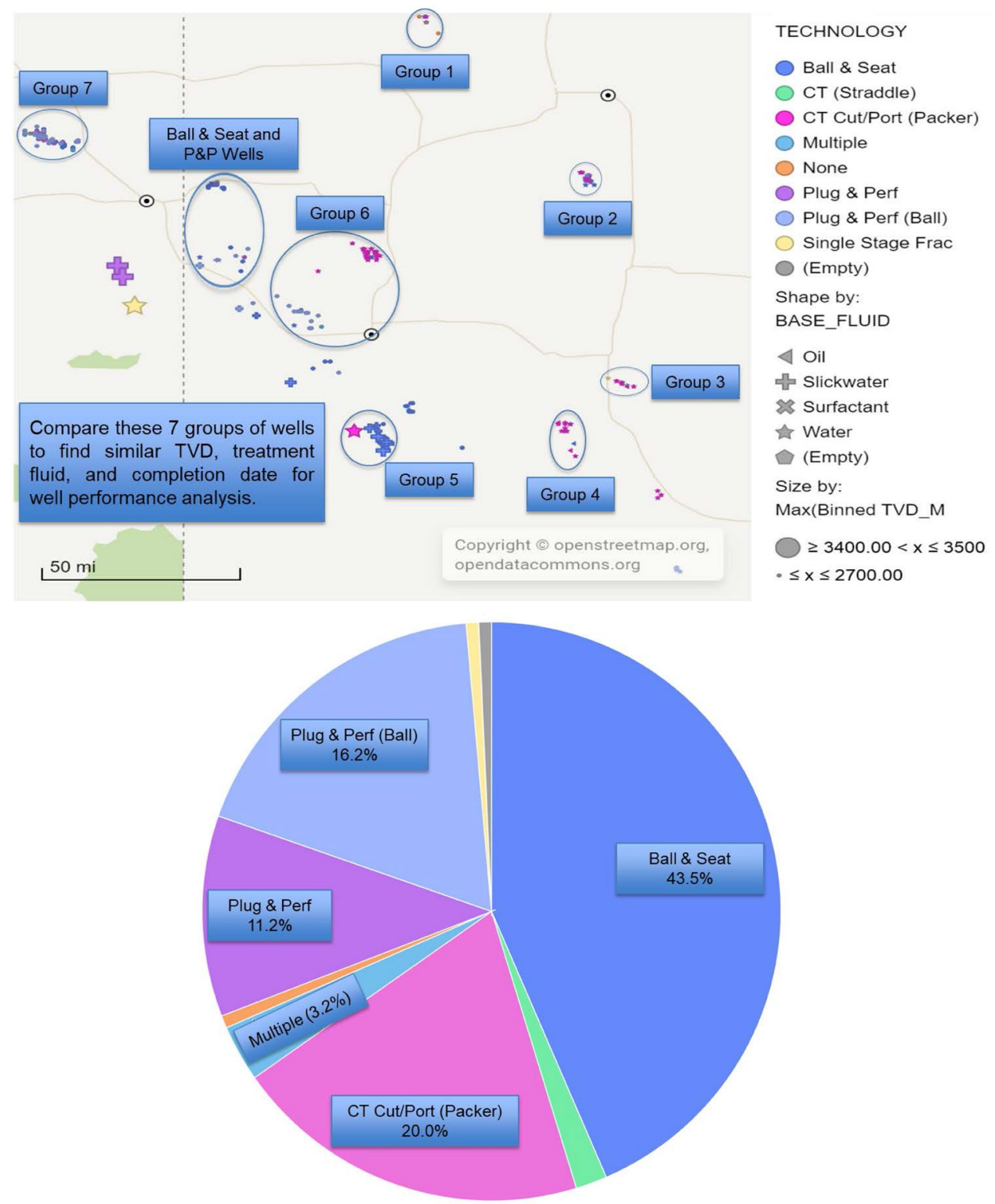

Of the total seven groups of wells analyzed, six groups have enough production data (12-month) to allow a comparison between the performance of pinpoint wells versus that of PnP (with ball) and ball-and-seat offsets. Of the total six groups of wells with 12-month production data available, two groups do not have any offsets using PnP/PnP (ball) and ball-and-seat completions to allow a comparison between the pinpoint completion performance versus PnP (with ball) and ball-and-seat completions. Of the remaining four groups, in three groups of wells, both 12-month production and normalized 12-month production (by completed length, proppant tonnage, and fluid volume) show that pinpoint completions generally outperform their PnP (with ball) and ball-and-seat offsets. Two samples of these groups (Groups 4 and 6) are shown in Figs. 7 and 8. The pinpoint wells that outperform their PnP (with ball) and ball-and-seat offsets render similar TVD (1800-1900 m), completion fluid (either slickwater or hybrid), and completion date (2011-2013).

One ball-and-seat offset that outperforms most of its pinpoint offsets (except one) in one group of wells has been completed 2 to 3 years earlier (2010) at a higher local reservoir pressure (and in a sweet spot), and it has a similar TVD $(1800 \mathrm{~m})$. This group of wells (Group 6) is shown in Fig. 8.

\section{Operator C (Tupper/Heritage)}

According to Fig. 9, Operator $\mathrm{C}$ has completed a total of 265 wells in Tupper/Tupper West/Heritage areas of the Montney (Q4, 2019). Approximately $17 \%$ of these wells are pinpoint wells, while $61 \%$ use the ball-andseat completion method and the remaining $20 \%$ wells 
Fig. 7 Comparison of well completion-type performance (normalized by completed lateral length and total fluid/ proppant placed) for Company B (Wells Group 4) based on treatment fluid, completion date, TVD, total fluid pumped, and total proppant placed
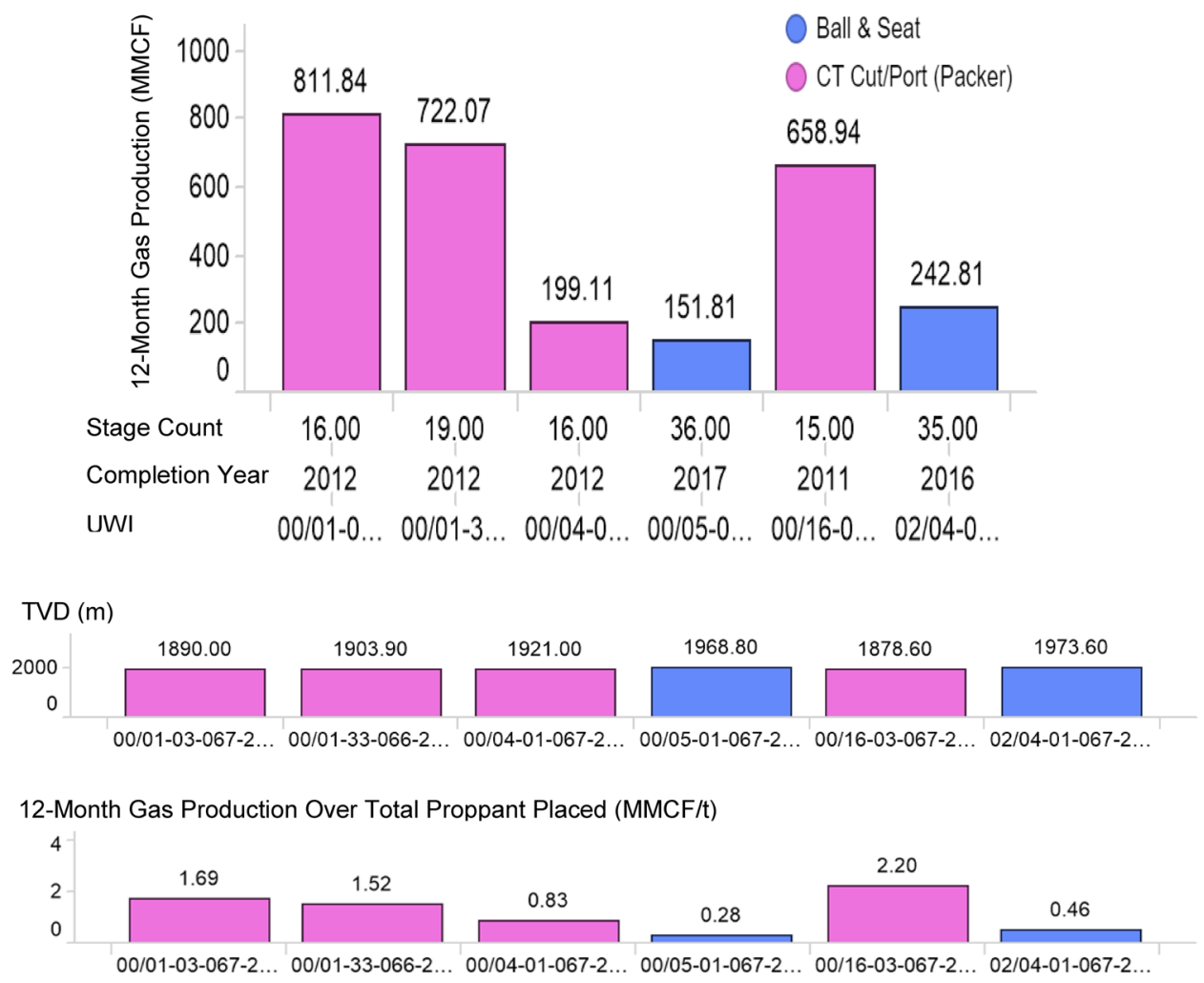

12-Month Gas Production Over Lateral Length ( $\mathrm{MBO} / \mathrm{m})$

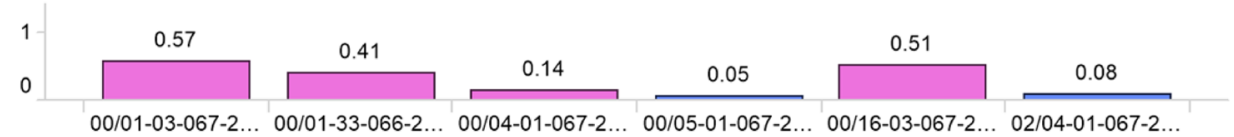

12-Month Gas Production Over Total Fluid Pumped (MMCF $/ \mathrm{m}^{3}$ )

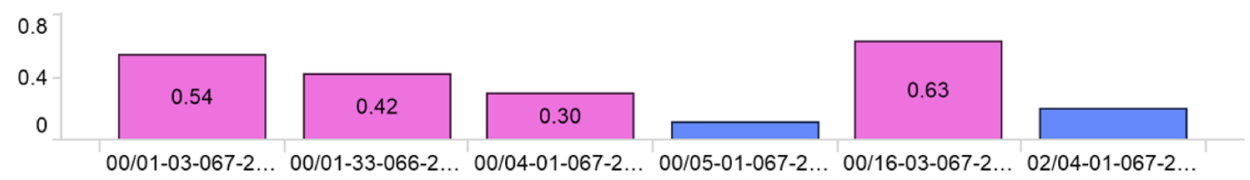

Total Fluid Pumped $\left(\mathrm{m}^{3}\right)$

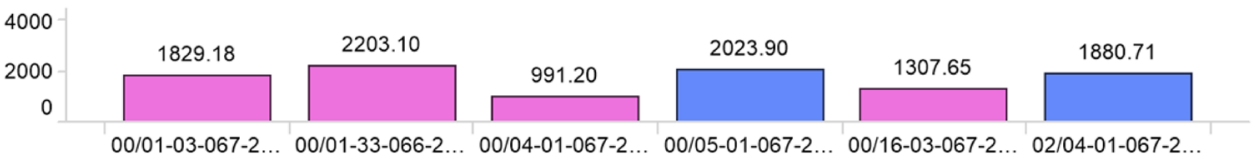

Total Proppant Placed ( $\mathrm{t}$ )

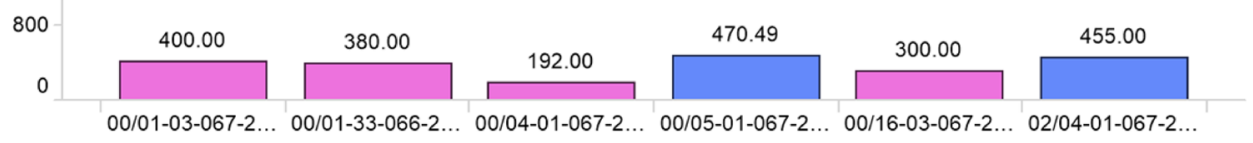

were completed with either traditional PnP or PnP (with ball) methods. The comparison of 12-month production for the pinpoint wells versus their nearby PnP (with ball) and ball-and-seat offsets considers wells that have similar completion fluids (slickwater, surfactant foam, oil-based, and water hybrid), TVD (range of mostly 1800-2800 m), and preferably similar completion date. These clustering criteria resulted in five groups of offset wells.

Of the five groups of offset wells compared, both 12-month production and normalized 12-month production (by completed length, proppant tonnage, and fluid volume) in three groups of wells generally show that 
Fig. 8 Comparison of well completion-type performance (normalized by completed lateral length and total fluid/ proppant placed) for Company B (Wells Group 6) based on treatment fluid, completion date, TVD, total fluid pumped, and total proppant placed
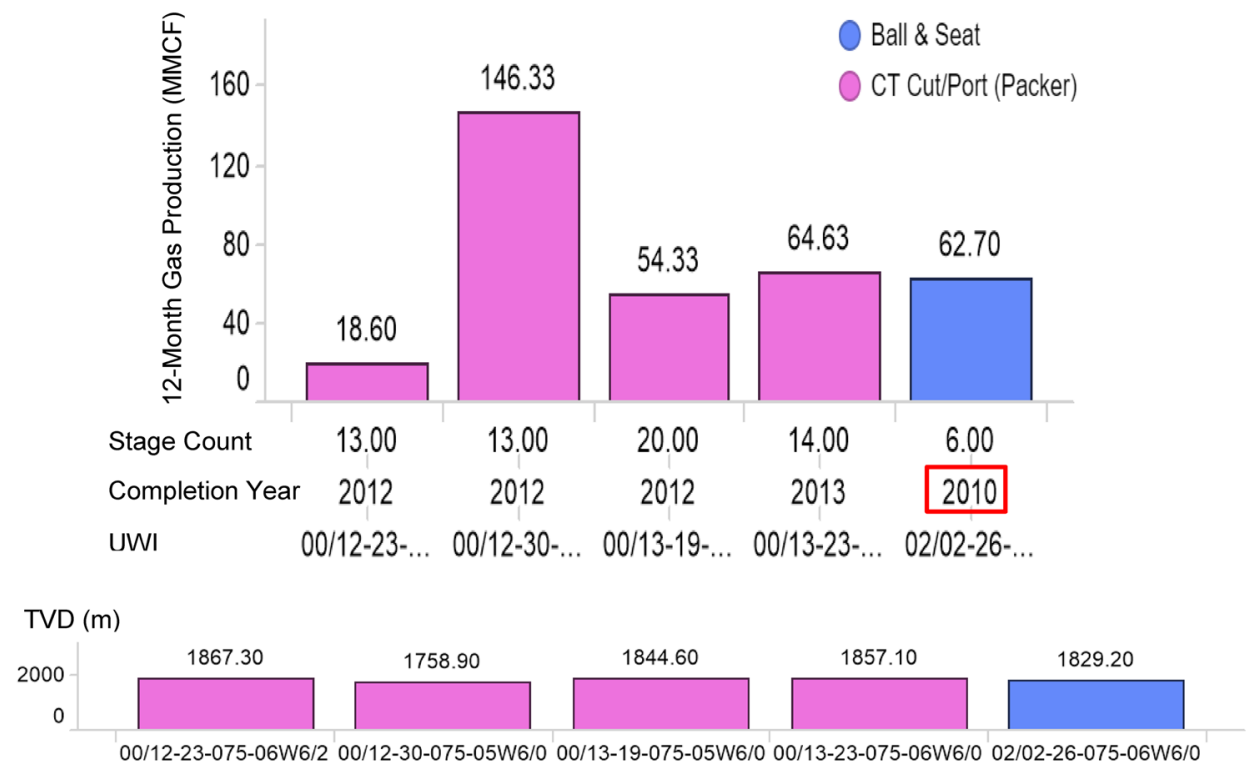

12-Month Gas Production Over Total Proppant Placed (MMCF/t)

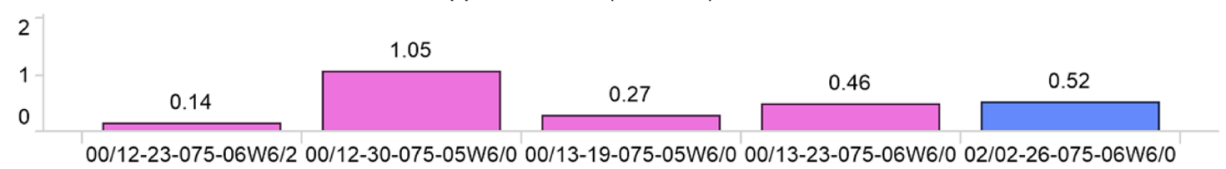

12-Month Gas Production Over Lateral Length (MBO/m)

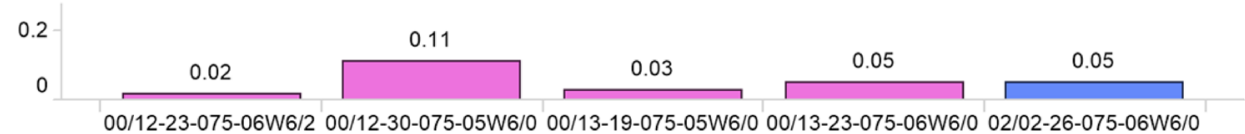

12-Month Gas Production Over Total Fluid Pumped (MMCF/m³)

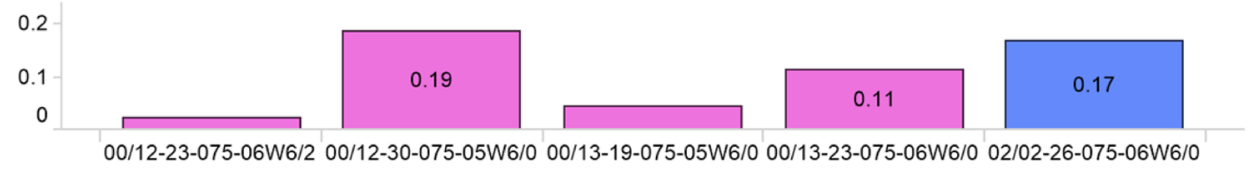

Total Fluid Pumped $\left(\mathrm{m}^{3}\right)$
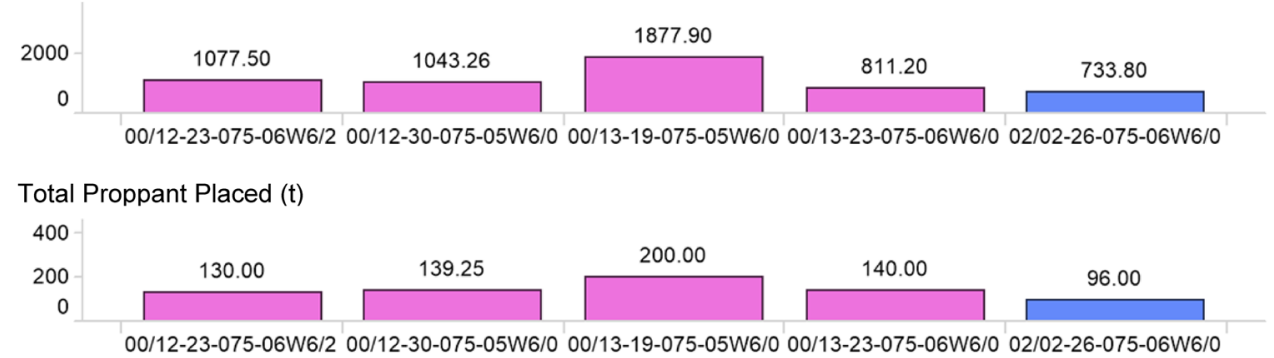

the pinpoint completions outperform their PnP and balland-seat offsets in Tupper/Tupper West/Heritage area. These outperforming pinpoint wells exhibit similar TVD (1800-2800 m), completion fluids $\left(\mathrm{N}_{2}\right.$-energized oil-based fluid or water-based hybrid), and completion date to their $\mathrm{PnP}$ and ball-and-seat offsets. Figure 10 shows one sample group (Group 1) of these wells.
One ball-and-seat offset that outperforms most of its pinpoint offsets (except one) in one group of wells has been completed 1-2 years earlier at a higher local reservoir pressure. Another outperforming ball-and-seat offset has been completed 1-2 years earlier (at higher local reservoir pressure) and used $\mathrm{N}_{2}$-energized oil-based fluid versus either water-based (hybrid) or surfactant $\left(\mathrm{N}_{2}\right.$ foam) used in 
Fig. 9 Top: wells grouping for Company $\mathrm{C}$ based on similar TVD, treatment fluid, and completion date to compare the performance of completion types; bottom: well counts and percentage by completion type
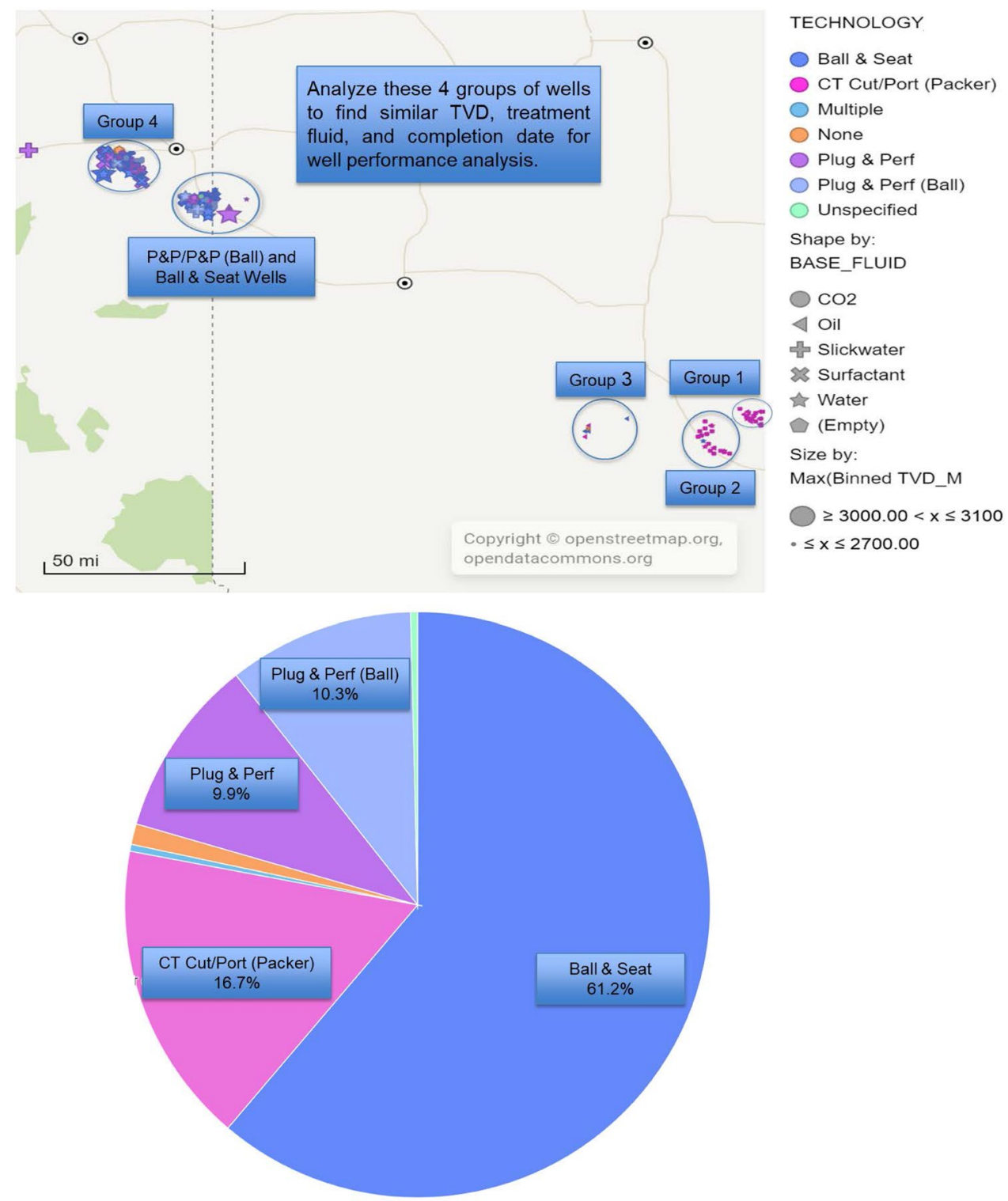

pinpoint offsets in a tight siltstone formation sensitive to water-phase trapping. Figure 11 shows one sample group (Group 2) of these wells.

\section{Operator D (Kakwa and Wapiti)}

There are 39 wells completed by Operator D in Kakwa/ Wapiti areas of the Montney (Q4, 2019). Approximately, $67 \%$ of these wells were completed with pinpoint technology (Fig. 12). Each of the PnP (ball) and ball-and-seat completions was used in approximately $15 \%$ of the wells in these two areas of the Montney. Figure 12 depicts the wells grouping for comparing the 12-month production for the pinpoint wells versus their nearby $\mathrm{PnP}$ (with ball) and balland-seat offsets that have similar completion fluid (SW or hybrid), TVD (3300-3400 m), and preferably similar completion date.

The sample results of this analysis are shown in Figs. 13 and 14 (Groups 1 and 2). Both 12-month production and normalized 12-month production (by completed length and proppant tonnage) show that the pinpoint completions outperform their PnP (with ball) and ball-and-seat offsets in the Kakwa area of the Montney. These outperforming pinpoint wells exhibit similar TVD (3300-3400 m), completion fluid (either slickwater or hybrid), and completion date (2014-2017) to their PnP (with ball) and ball-andseat offsets. 
Fig. 10 Comparison of well completion-type performance (normalized by completed lateral length and total fluid/ proppant placed) for Company C (Wells Group 1) based on treatment fluid, completion date, TVD, total fluid pumped, and total proppant placed
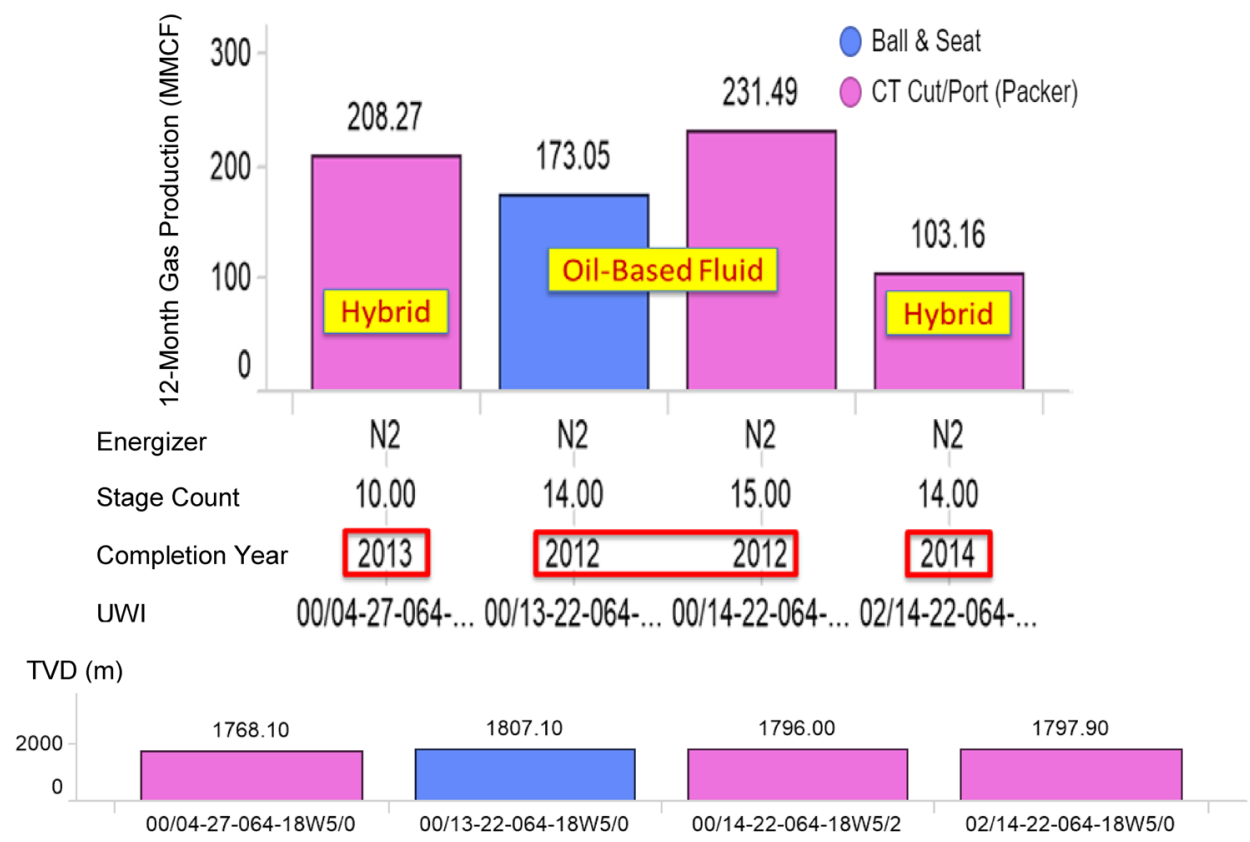

12-Month Gas Production Over Total Probnant Placed (MMCF/t)

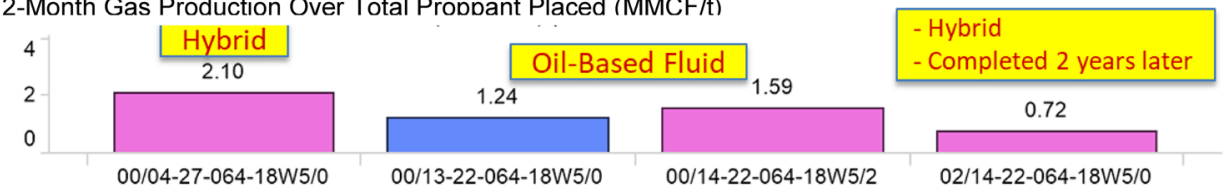

12-Month Gas Production Over Lateral Length (MBO/m)
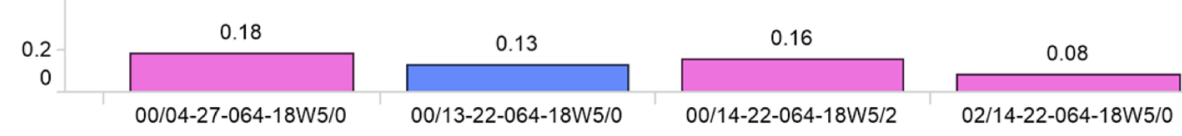

12-Month Gas Production Over Total Fluid Pumped (MMCF/m³)
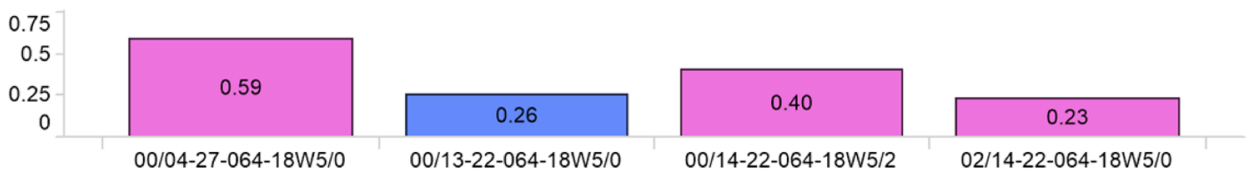

Total Fluid Pumped $\left(\mathrm{m}^{3}\right)$
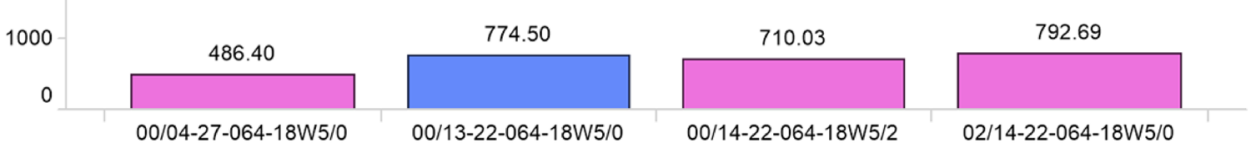

Total Proppant Placed (t)
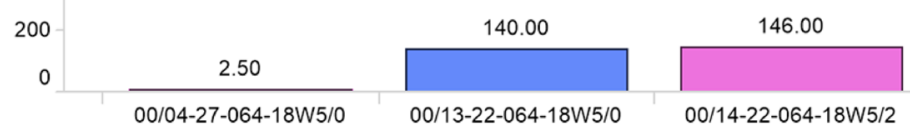

02/14-22-064-18W5/0

\section{Operator E (northern Montney)}

A total of 62 wells have been completed by Operator E in the Northern Montney (Q4, 2019), with 45\% of these wells being fractured using the pinpoint technology, and $48 \%$ using the ball-and-seat method (Fig. 15). The clustering criteria resulted in five groups of offset wells in this area to compare the 12-month production for the pinpoint wells versus their nearby ball-and-seat offsets that have similar completion fluid (slickwater and water hybrid), TVD (range of mostly $1400-1800 \mathrm{~m}$ ), and preferably similar completion date. 
Fig. 11 Comparison of well completion-type performance (normalized by completed lateral length and total fluid/ proppant placed) for Company C (Wells Group 2) based on treatment fluid, completion date, TVD, total fluid pumped, and total proppant placed

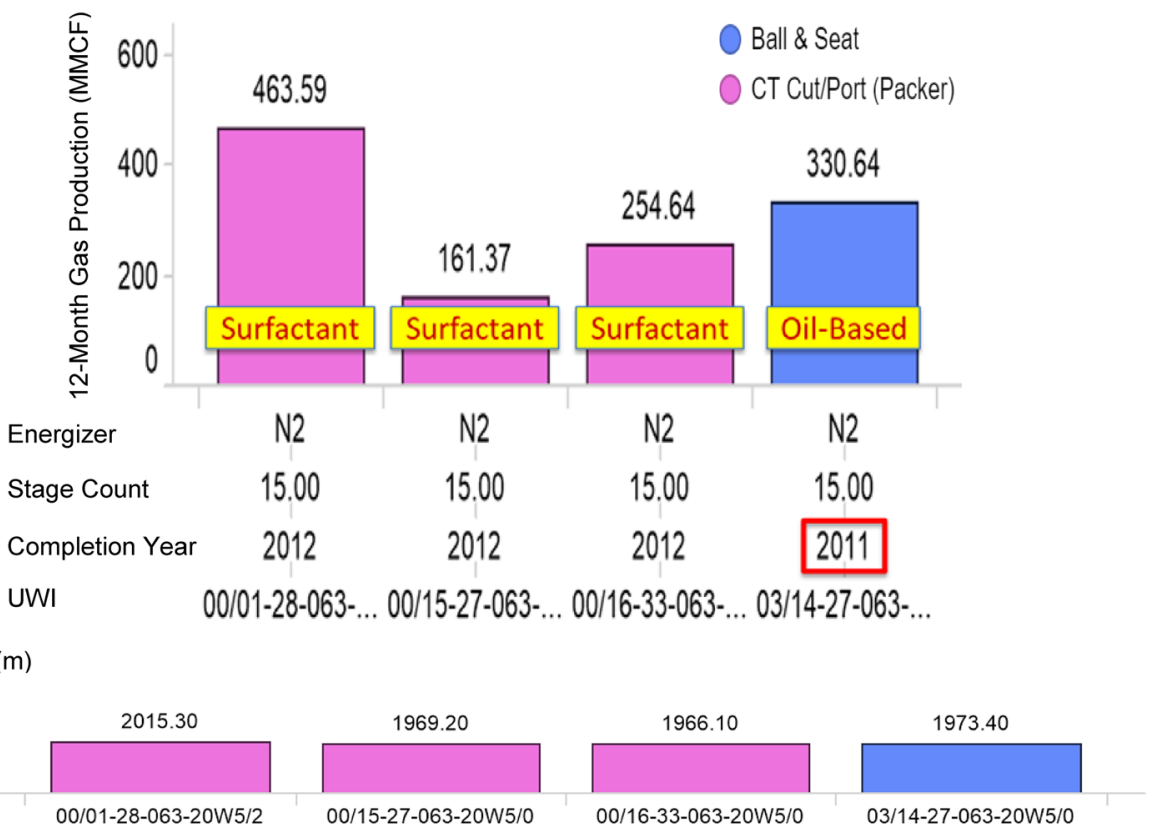

12-Month Gas Production Over Total Proppant Placed (MMCF/t)

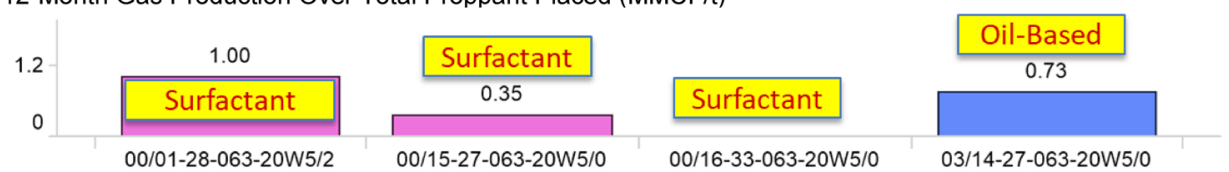

12-Month Gas Production Over Lateral Length ( $\mathrm{MBO} / \mathrm{m})$

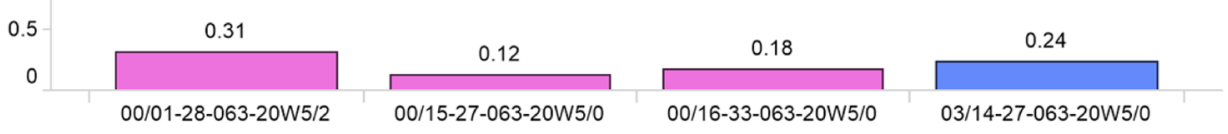

12-Month Gas Production Over Total Fluid Pumped (MMCF $/ \mathrm{m}^{3}$ )

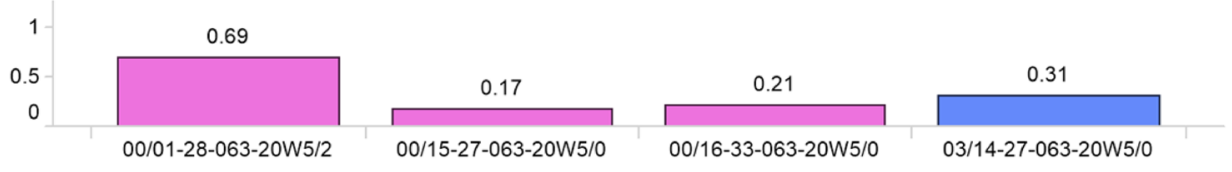

Total Fluid Pumped $\left(\mathrm{m}^{3}\right)$

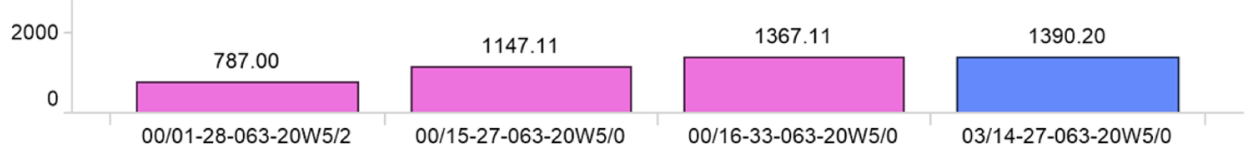

Total Proppant Placed (t)

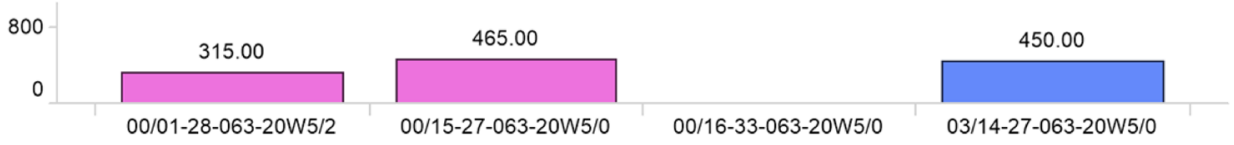

Of the three groups with 12-month production data available, in two groups of wells, both 12-month production and normalized 12-month production (by completed length, proppant tonnage, and fluid volume) show pinpoint completions generally outperforming their ball-and-seat offsets in in the Northern Montney area. The pinpoint wells that outperform their ball-and-seat offsets in two groups of wells render similar TVD (1400-1800 m), completion fluid (no-energizer slickwater), and completion date. Figure 16 shows a sample group of these wells (Group 1). Also, Fig. 17 shows the completion-performance comparison of the wells in Group 3 in which the pinpoint wells (completed in 2016) outperform their ball-and-seat offsets (completed in 2014) despite depletion (pinpoint wells completed 2 years later). 
Fig. 12 Top: wells grouping for Company $\mathrm{D}$ based on similar TVD, treatment fluid, and completion date to compare the performance of completion types; bottom: well counts and percentage by completion type
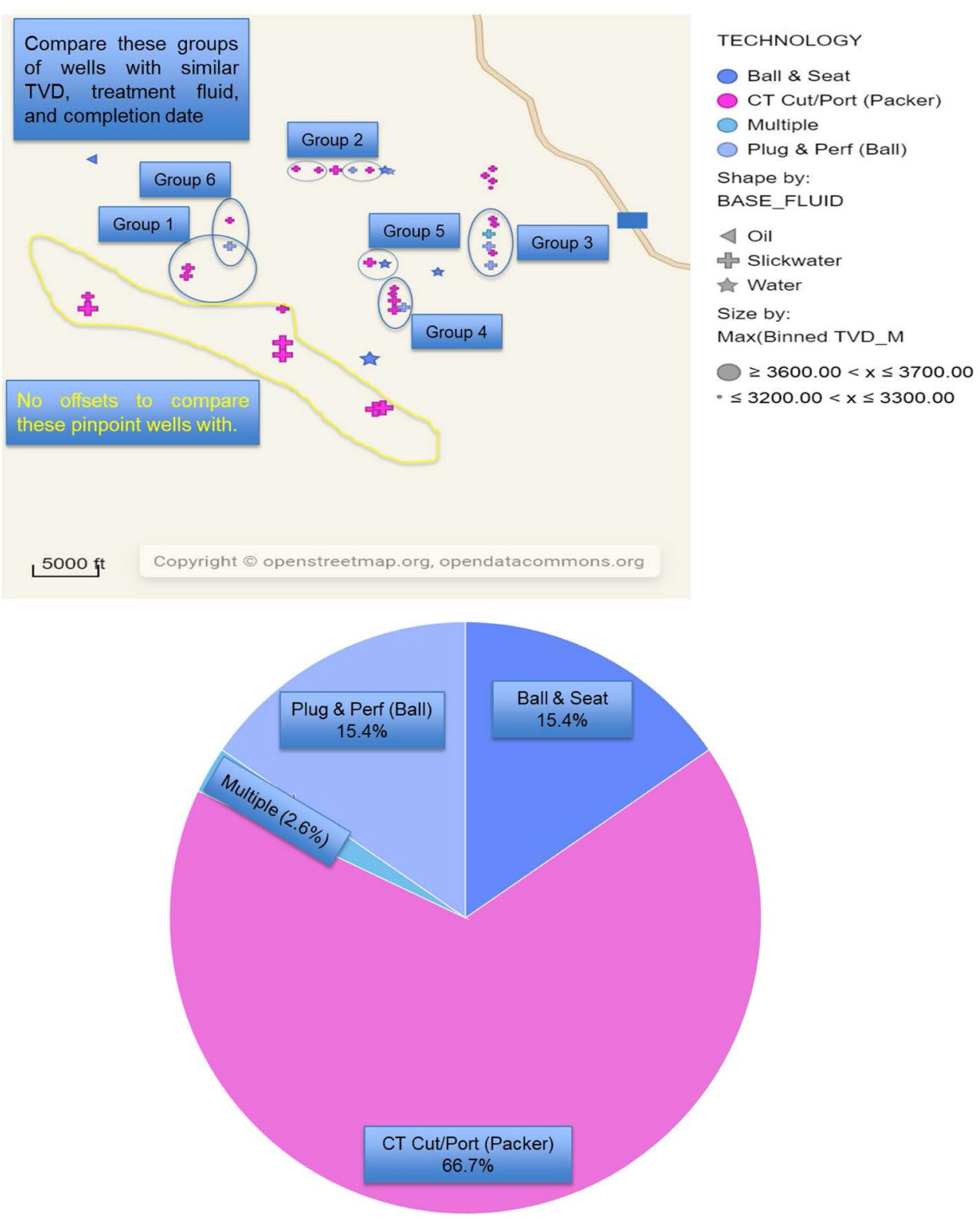

One ball-and-seat well that outperforms its pinpoint offsets in 1 group (Group 2 shown in Fig. 18) of wells has been completed 2 years earlier (at higher local reservoir pressure) and used energizer slickwater as the fracturing fluid versus the slickwater fluid used in completing the pinpoint offsets.

\section{Operator F (Heritage)}

Figure $19 \mathrm{a}, \mathrm{b}$ shows the grouping of wells to compare the 12-month production for the pinpoint wells versus their nearby PnP (with ball) and ball-and-seat offsets that have similar completion fluid (slickwater, surfactant foam, oil-based, and water hybrid), TVD (range of mostly $1800-2100 \mathrm{~m}$ ), and preferably similar completion date. Of the total ten groups of wells, five groups do not have any offsets with pinpoint completions to allow a comparison between the pinpoint completion performance versus that of PnP (with ball) and ball-and-seat completions. The reason is that of the total of 585 wells completed by the Operator F in the Heritage area of the Montney (Q4, 2019), only 6\% were completed using pinpoint fracturing. Majority of the wells have been completed with PnP (ball) (48\%) and balland-seat (32\%) methods.

Of the five groups with 12-month production data available, in three groups of wells, both 12-month production and normalized 12-month production (by completed length and proppant tonnage) show that the pinpoint completions generally outperforming their ball-and-seat offsets in the Heritage area operated by Company F. The pinpoint wells that outperform their ball-and-seat offsets in three groups of 
Fig. 13 Comparison of well completion-type performance (normalized by completed lateral length and total fluid/ proppant placed) for Company D (Wells Group 2) based on treatment fluid, completion date, TVD, total fluid pumped, and total proppant placed
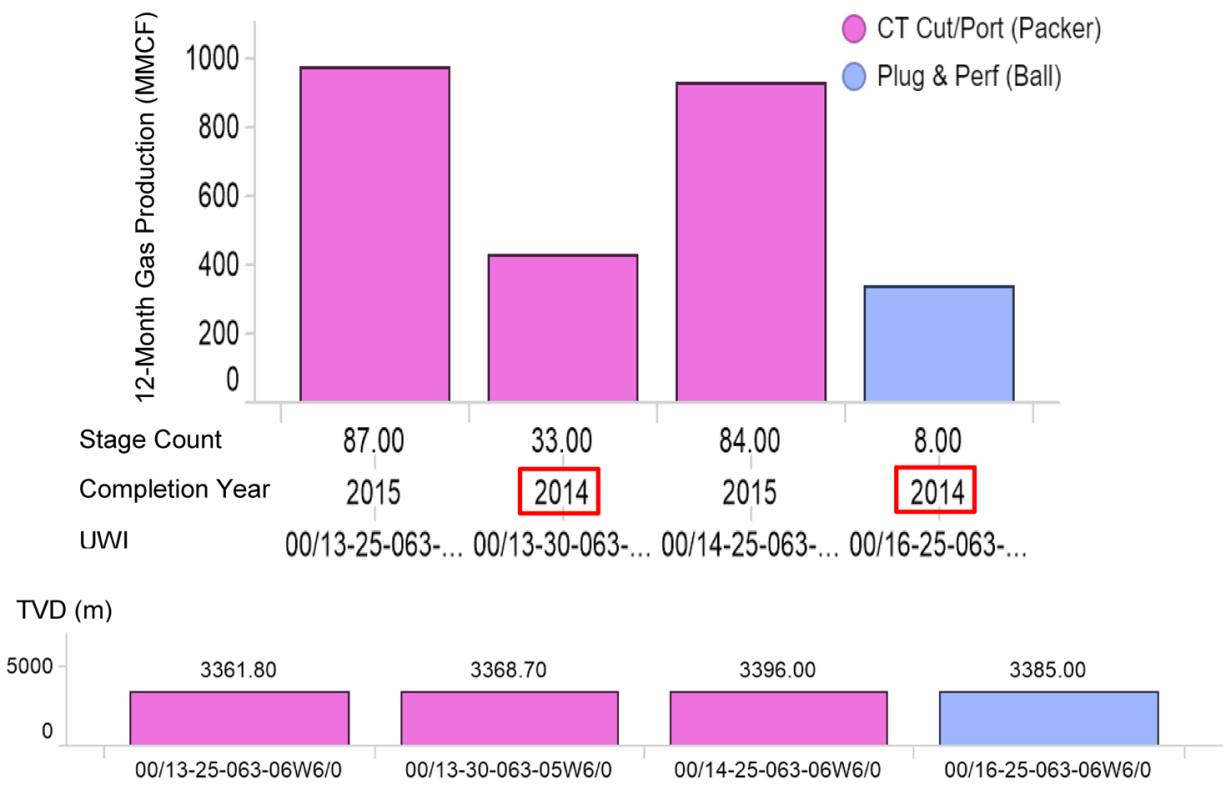

12-Month Gas Production Over Total Proppant Placed (MMCF/t)

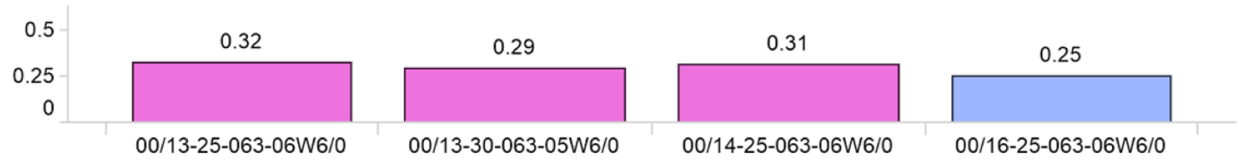

12-Month Gas Production Over Lateral Length (MBO/m)
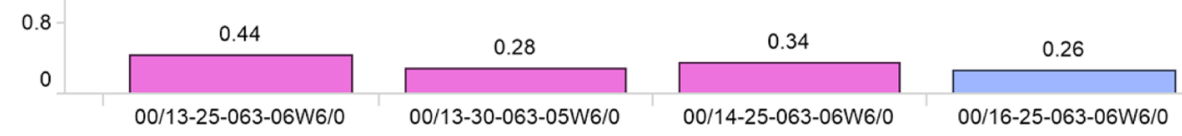

Total Fluid Pumped (MMCF/m³)
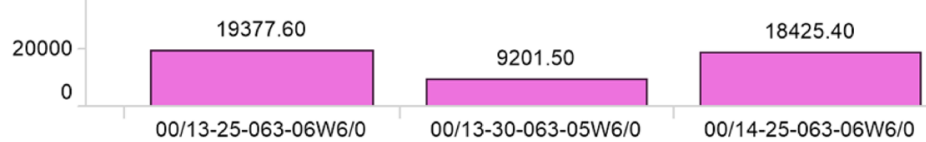

\subsection{3}

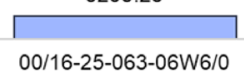

Total Proppant Placed ( $\mathrm{t})$
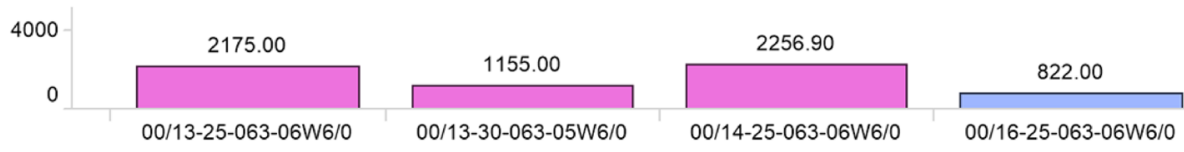

wells render similar TVD (1900-2000 m) and completion fluid (mostly $\mathrm{N}_{2}$-energized water-based hybrid). Some of these pinpoint wells (completed in 2016-2017) outperform their ball-and-seat offsets (completed in 2011-2014) despite depletion, as these pinpoint wells completed 3-5 years later. In addition, the performance indicator of 12-month production normalized by fluid volume for these pinpoint wells does not outperform that of their ball-and-seat offsets, because significantly higher fluid volumes were injected into these pinpoint wells to compensate for the depletion as a result of the production from the ball-and-seat offsets. A sample of these groups is Group 7 (Fig. 20).

The ball-and-seat offsets that outperform their pinpoint offsets in two groups of wells have been completed $3-5$ years earlier (at higher local reservoir pressure) and/or used waterbased hybrid fluid versus slickwater used in pinpoint offsets. The performance of these two groups of wells (Groups 3 and $10)$ is given in Figs. 21 and 22. 
Fig. 14 Comparison of well completion-type performance (normalized by completed lateral length and total fluid/ proppant placed) for Company D (Wells Group 1) based on treatment fluid, completion date, TVD, total fluid pumped, and total proppant placed

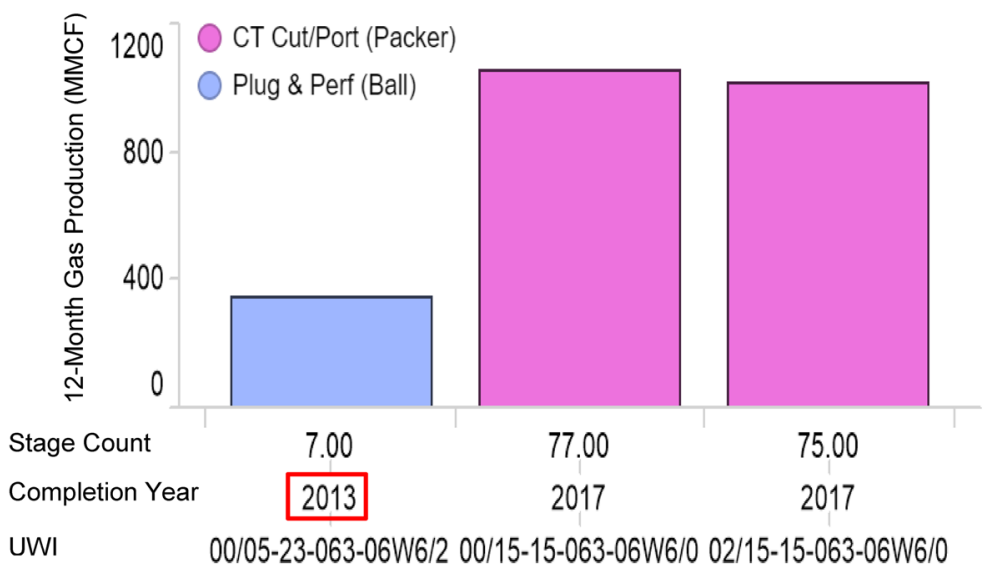

TVD (m)

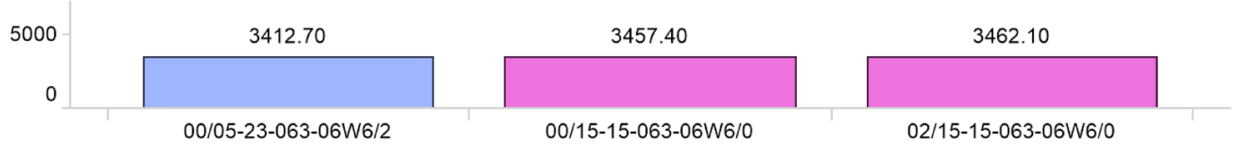

12-Month Gas Production Over Total Proppant Placed (MMCF/t)

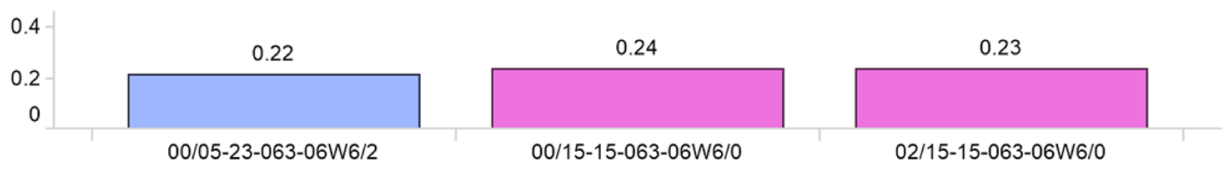

12-Month Gas Production Over Lateral Length ( $\mathrm{MBO} / \mathrm{m})$
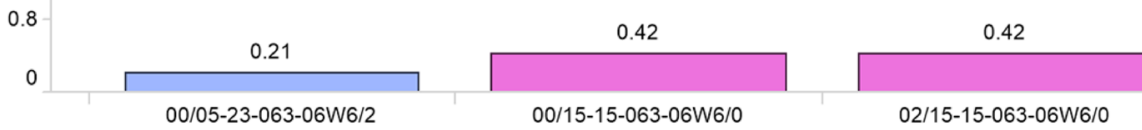

Total Fluid Pumped $\left(\mathrm{MMCF} / \mathrm{m}^{3}\right)$
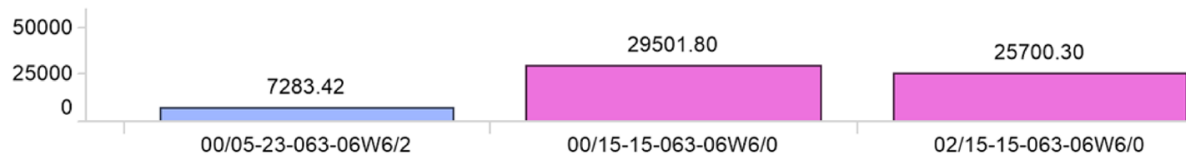

Total Proppant Placed (t)
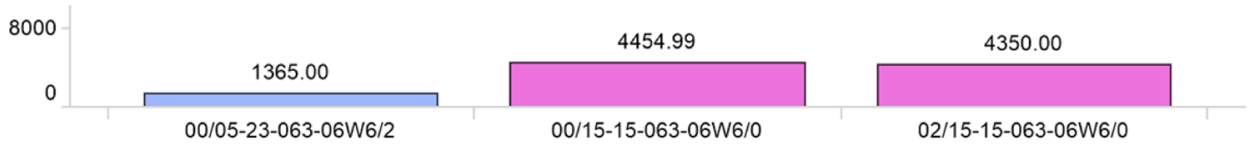

\section{Discussion: choosing an optimal completion system}

The previously reported reviews in the literature on the performance of fracturing methods in the Montney have not represented a consistent and comprehensive evaluation of these methods, because of some shortcomings, namely using a small sample size, having a limited scope (focusing on a specific aspect of fracturing, including method or fluid), relying on statistical approaches that offer limited subsurface insight, and generating misleading results (e.g., on optimum fracturing method/fluid) through using disparate data that are often unstructured, and hence, become untrustworthy. The latter has arisen owing to a significant regional variation in TVD, petrophysical properties, fluid windows, completed lateral length, fracturing method/ fluid/date, and drawdown rate management. This review eliminated these shortcomings by rigorously clustering more than 4000 Montney wells by taking into consideration the TVD, geological properties, fluid window, completed lateral length, fracturing method/fluid/date, and drawdown strategy. This type of clustering isolated the effect of each fracturing method by comparing the production of each well to that of its offsets, which use different fracturing methods but possess similar geology in the same fluid window. 
Fig. 15 Top: wells grouping for Company E based on similar TVD, treatment fluid, and completion date to compare the performance of completion types; bottom: well counts and percentage by completion type
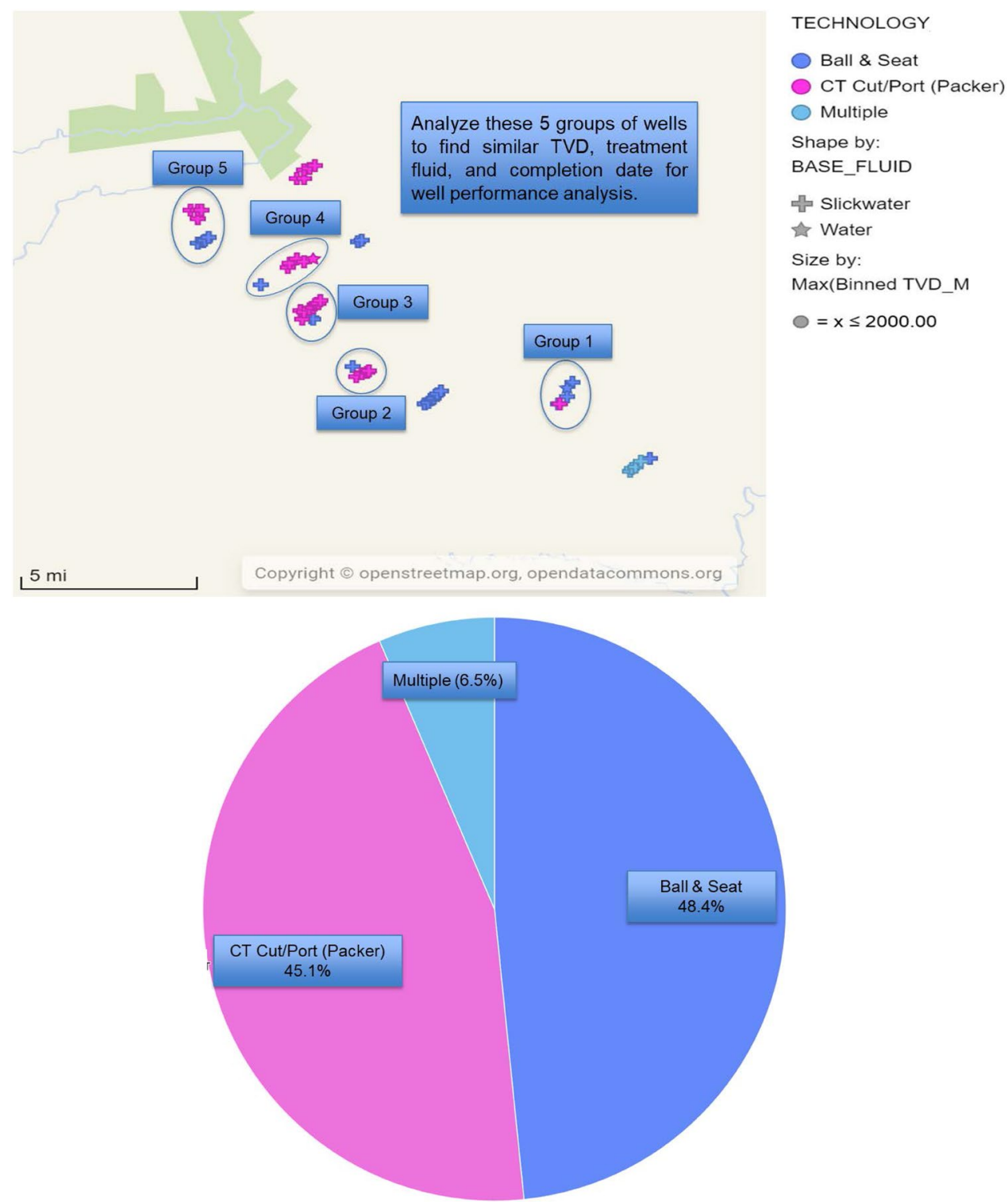

The results overwhelmingly reveal that with similar TVD and fracturing fluid/date, wells completed with pinpoint fracturing outperform their offsets completed with ball-and-seat and PnP fracturing. However, wells completed with ball-and-seat and PnP methods that outperform their offset pinpoint wells have either been fractured one to four years earlier than pinpoint wells and/or used energized oil-based fluid, hybrid fluid, and energized slickwater versus slickwater used in the pinpoint offsets. This clearly suggests that the water-phase trapping is more severe in these pinpoint wells because of using slickwater. Previous studies often favored one specific fracturing method or fluid without highlighting these complex interplays between the type of fracturing method/fluid, completion date (regional depletion), and the reservoir properties and hydrodynamics. The completion method should therefore be selected in the context of regional depletion and fluid type.

The analysis reveals that the formation damage from the water-based completion fluids is attributable to the waterphase trapping as a result of the imbibition of water-based treatment fluids in the presence of high capillary pressures in the tight siltstone rock. Because most of the Montney wells are typically choked (partly to avoid rapid hydraulic-fracture closure as a result of proppant crushing attributable to the rise in the net vertical in situ stress during the flowback and production), the typical drawdown pressures applied to the Montney wells during the operation do not reach the threshold capillary pressures required to mobilize and produce the trapped water-based completion fluids. Hence, some of the imbibed treatment fluid remains trapped during the flowback, fracture cleanup, and the production periods. To 
Fig. 16 Comparison of well completion-type performance (normalized by completed lateral length and total fluid/ proppant placed) for Company E (Wells Group 1) based on treatment fluid, completion date, TVD, total fluid pumped, and total proppant placed
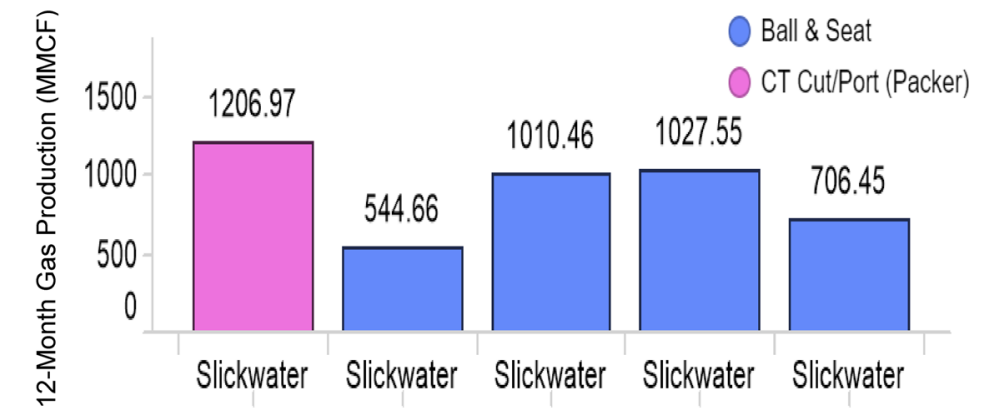

Energizer

$\begin{array}{llllll}\text { Stage Count } & 65.00 & 35.00 & 35.00 & 35.00 & 35.00 \\ \text { Completion Year } & 2016 & 2017 & 2017 & 2017 & 2017\end{array}$

UWI 00/A-091- 00/C-100- 02/A-091- 02/C-100- 03/C-100D/094-H-O... C/094-H-O... D/094-H-O ... C/O94-H-O ... C/094-H-O...

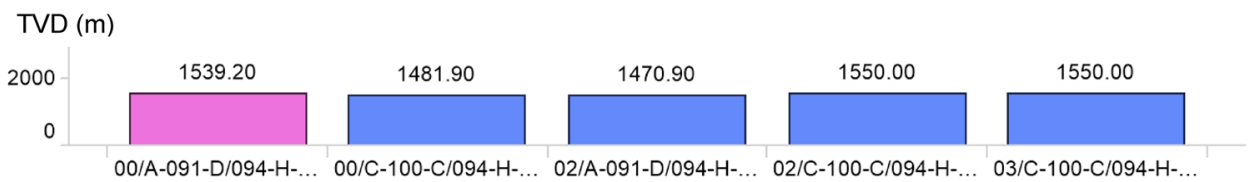

12-Month Gas Production Over Total Proppant Placed (MMCF/t)

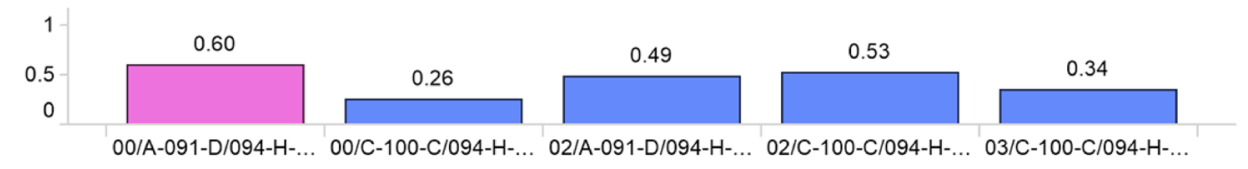

12-Month Gas Production Over Lateral Length $(\mathrm{MBO} / \mathrm{m})$

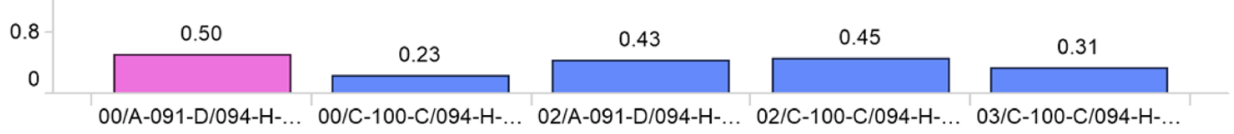

12-Month Gas Production Over Total Fluid Pumped (MMCF $/ \mathrm{m}^{3}$ )

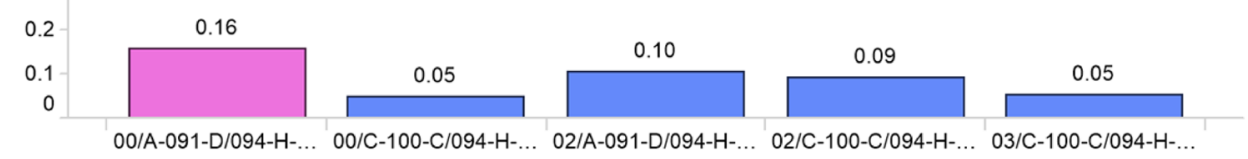

Total Fluid Pumped $\left(\mathrm{m}^{3}\right)$

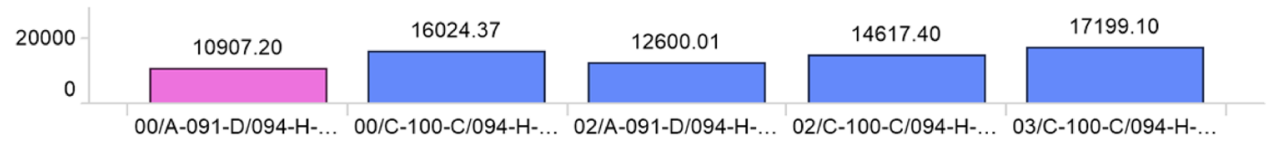

Total Proppant Placed ( $\mathrm{t}$ )

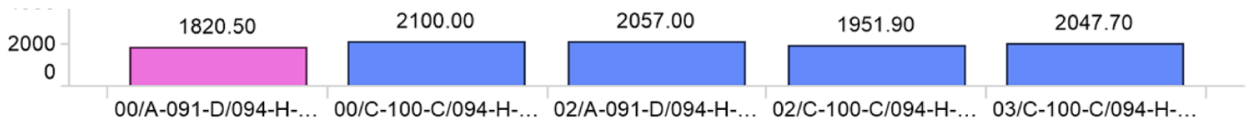

mitigate or reduce the fluid-phase trapping, energized fluids (addition of $\mathrm{N}_{2}$ or $\mathrm{CO}_{2}$ or a combination of both gases) can be used with qualities typically less than $50 \%$. There is overwhelming evidence that the use of energized completion fluids can improve the treatment fluid recovery in the watersensitive Montney siltstone by reducing the trapped water saturation (Kong et al. 2017; Reynolds et al. 2014). Primary reasons that discourage the use of energized water-based and oil-based treatment fluids in the Montney include the initial upfront costs of energized and foam fluids in comparison with slickwater and possibly hybrid fluid systems, as well as some of the operational and logistical complications in 
Fig. 17 Comparison of well completion-type performance (normalized by completed lateral length and total fluid/ proppant placed) for Company E (Wells Group 3) based on treatment fluid, completion date, TVD, total fluid pumped, and total proppant placed
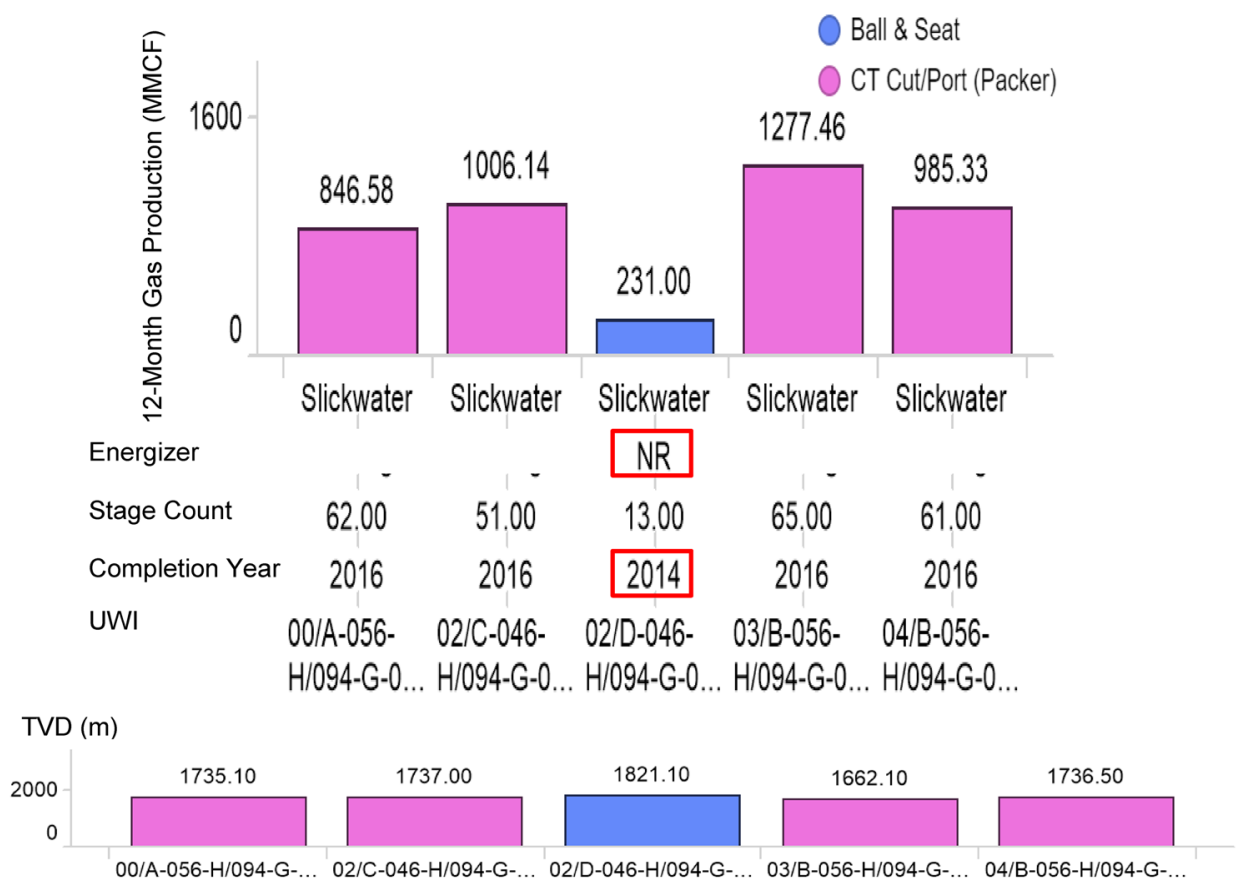

12-Month Gas Production Over Total Proppant Placed (MMCF/t)

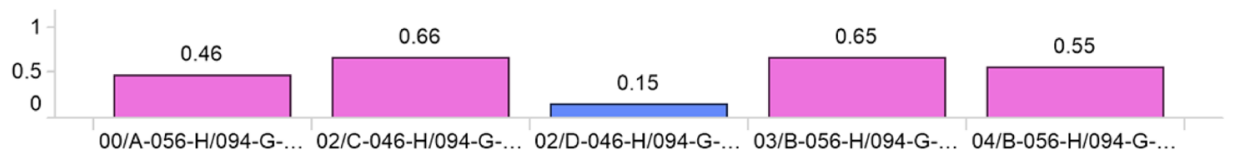

12-Month Gas Production Over Lateral Length (MBO/m)

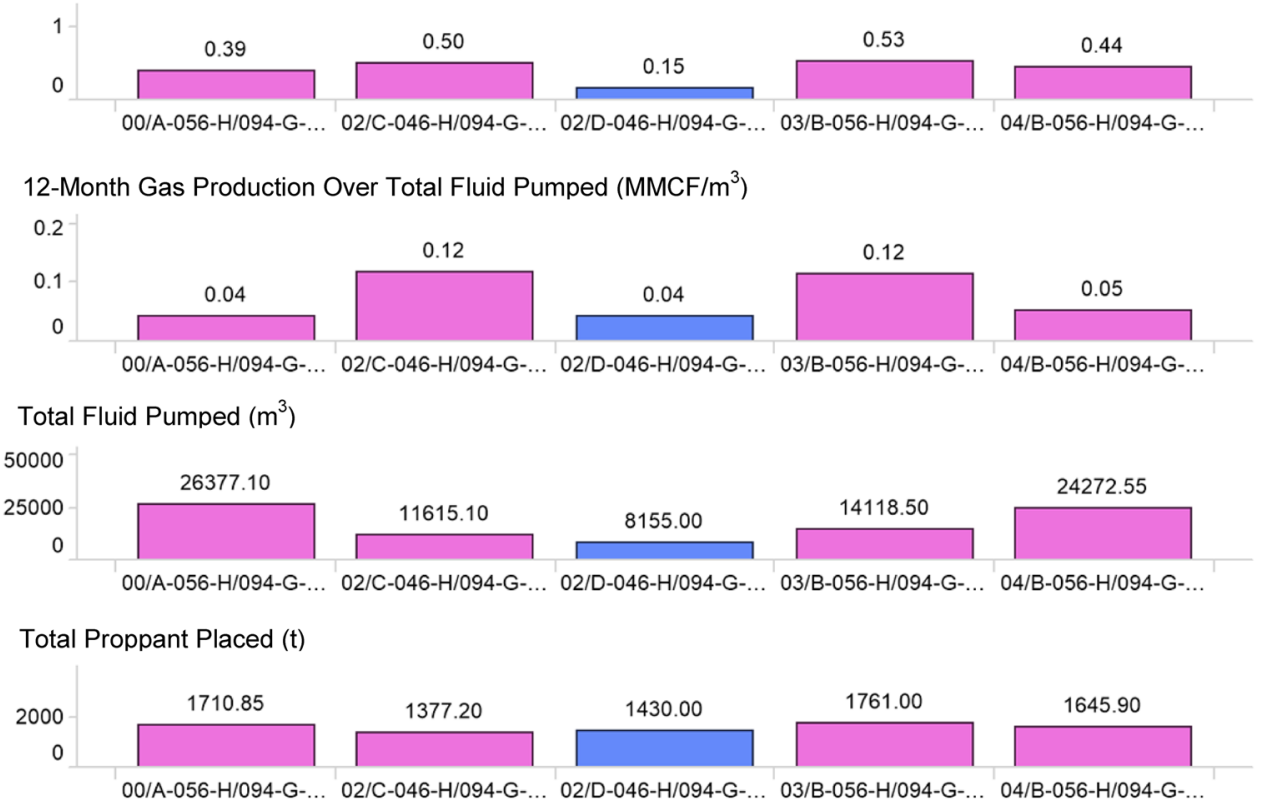

executing these fracturing treatments. In addition, there are reasons to speculate that the use of energized and foamed fluids in tight liquid-rich areas may in fact retard or even reduce the condensate yield and/or its recovery rate. The latter can delay the economic payout of a tight well. Although operators can get away with using nonenergized water-based treatment fluids in the higher-reservoir-quality areas of the Montney, the use of energized water-based fluids or oilbased (e.g., liquefied-petroleum-gas fluids) is warranted in the lower-quality parts, as these areas are most sensitive to the water-phase trapping issue, as it was shown by Reynolds et al. (2015). Thus, an efficient recovery of the fracturing 
Fig. 18 Comparison of well completion-type performance (normalized by completed lateral length and total fluid/ proppant placed) for Company E (Wells Group 2) based on treatment fluid, completion date, TVD, total fluid pumped, and total proppant placed

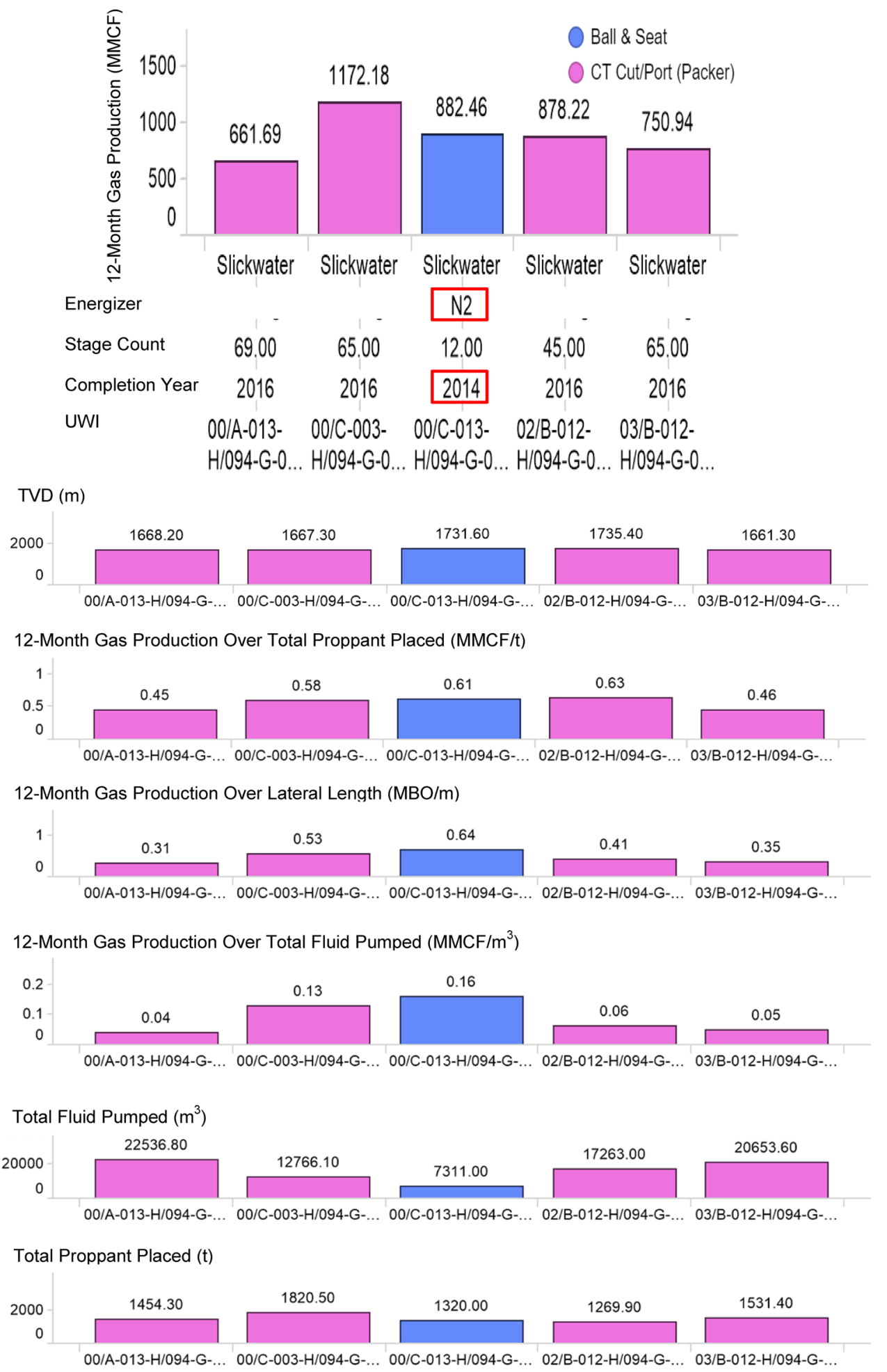

fluid is still one of the major considerations to achieve economic wells in the Montney, as it was initially discussed by Taylor et al. (2010).

It is imperative to emphasize that in choosing an appropriate completion method, the optimum well production performance is just one piece of the puzzle. Ample operational and subsurface evidence suggests that there is no single preferred or optimal completion method or fluid across the Montney play. A combination of reservoir geological and geomechanical attributes (Soliman et al. 2008; Yadali Jamaloei 2019a), costs (Reynolds et al. 2015), well performance (this study), and operational/logistical considerations (Wellhoefer et al. 
Fig. 19 Top: wells grouping for Company $\mathrm{F}$ based on similar TVD, treatment fluid, and completion date to compare the performance of completion types; bottom: well counts and percentage by completion type

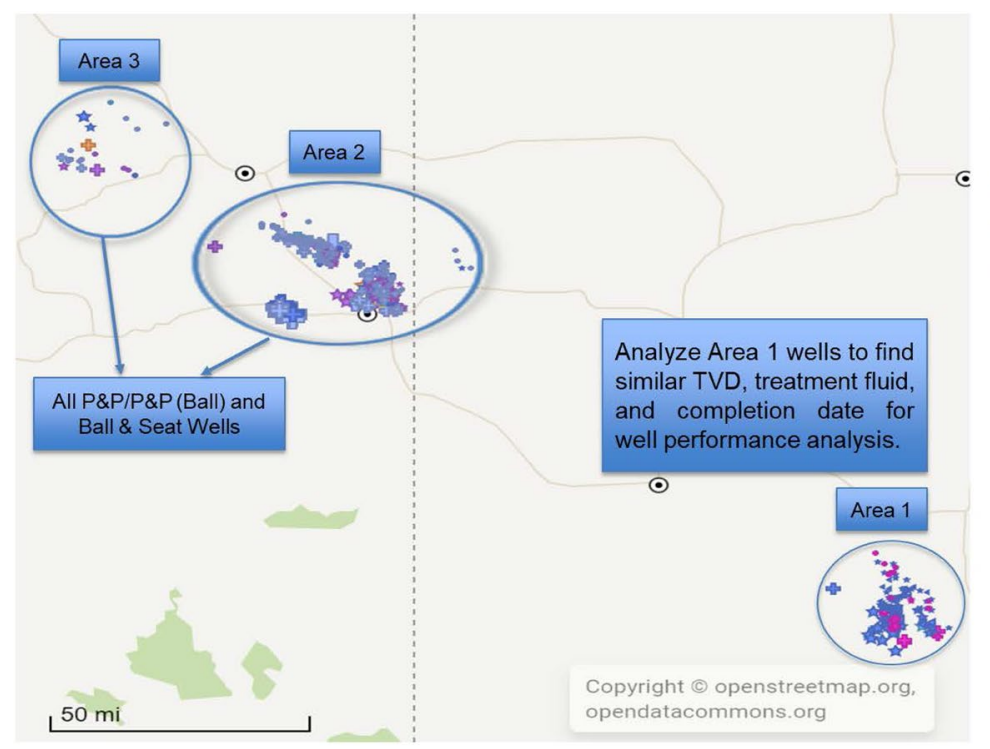

TECHNOLOGY

Ball \& Seat

CT Cut/Port (Packer)

Multiple

c

None

Plug \& Perf

Plug \& Perf (Ball)

Single Stage Frac

Shape by:

BASE_FLUID

$\triangle$ Oil

$=$ Other Acid

Slickwater

¿ Surfactant

Water

Size by:

Max(Binned TVD_M

$\geq 2800.00<x$

- $\leq x \leq 2000.00$

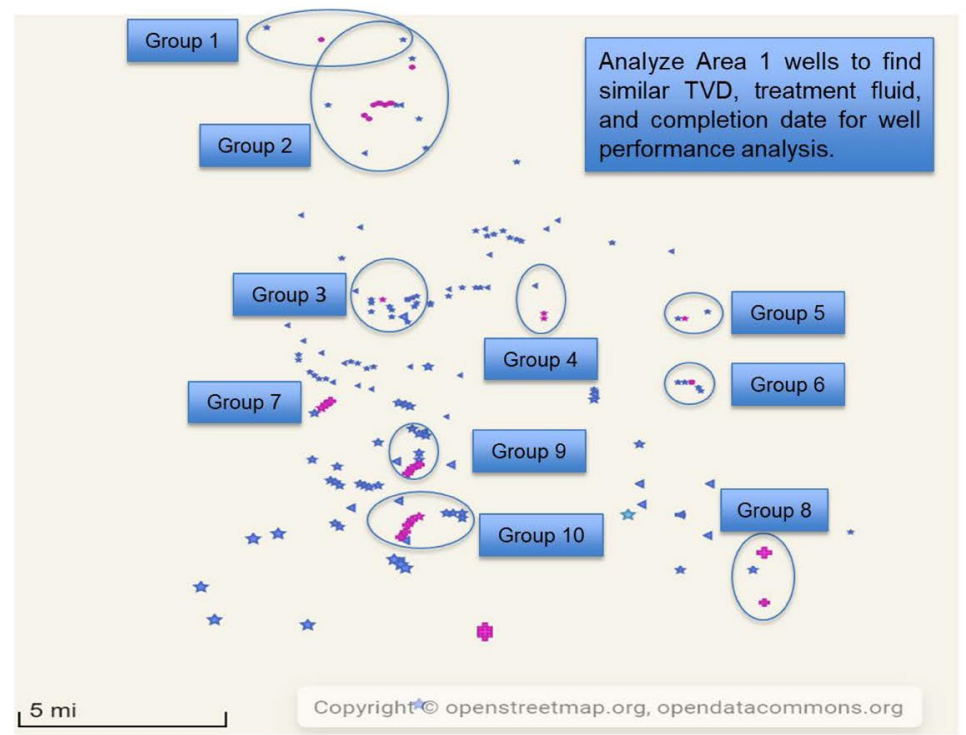

Ball \& Seat

CT Cut/Port (Packer)

Multiple

None

Plug \& Perf

Plug \& Perf (Ball)

Single Stage Frac

Shape by:

BASE_FLUID

$\triangle$ Oil

- Other Acid

Shlickwater

\&s Surfactant

는 Water

Size by:

Max(Binned TVD_M

$\geq 2800.00<x$

- $\leq x \leq 2000.00$
TECHNOLOGY
2014) determines the selection of an appropriate completion method and fluid.

Traditional PnP methods (Fig. 23) often use an electric wireline on which a fracture plug and perforating gun are deployed. After establishing a flow path at the toe (through a pressure-activated fracturing toe sleeve), a composite fracture plug is run on an electric wireline alongside a perforating gun. Once the tool aggregate is pumped to the desired depth, and the plug is set to isolate the underlying toe sleeve or stage, the perforating gun is then set at the desired position to create the prespecified number of perforation clusters. The perforating gun is then retrieved, and the fluid is pumped through the clusters in one single treatment. This procedure is repeated for all of the stages from the toe to the heel. The PnP methods exhibit several drawbacks in the Montney. The extent of perforation-cluster erosion is more significant than the erosion of the sleeve ports in ball-and-seat and pinpoints fracturing methods. The perforation discharge coefficient and pressure drop-which partly determine the fluid distribution among the clusters-are a strong function of the shaped charge and perforation gun efficiency in creating perfectly even-shaped, right-sized perforations. There are also stress halos generated around the perforations, which tend to activate more sites for the creation of axial fractures at the wellbore, and into the vicinity of the wellbore. Moreover, an external stress component exerted on the wellbore by the fracture plugs, which isolate the lower stage from the upper one, might increase the risk of wellbore breakdown along its axis, or microannulus fracturing because of the generation of axial fractures attributable to the change in stress concentration along the wellbore. The risk of leaking plugs might also compromise the isolation and treatment efficiency. Possible 
Fig. 19 (continued)

increased wellbore erosion in using high-pressure-graded, metal-contained composite fracture plugs should be also taken into consideration. Furthermore, in extended-reach wellbores, electric wireline reaching the target depth at the toe might not always be incident-free. Also, the use of CT, jointed pipe, and work strings in milling out the composite fracture plugs after the stimulation might involve both incidents and extra costs. Achieving an effective cement sheath isolation, which is the isolation method for PnP methods, is rather cumbersome in extended horizontal wellbores. The lapses in cement coverage (e.g., the presence of 'rat holes') along the wellbore or the lack of proper mechanical competence in designing the cement slurry might compromise the cement sheath integrity. Any compromise on the mechanical competence and integrity of the cement might trigger the loss of annular isolation, leading to an ineffective fracturing stimulation along the wellbore. Yadali Jamaloei (2020c) presents the downhole diagnostic evidence for cement integrity issues. Additionally, the interference that exists between multiple clusters of perforations in the limited entry $\mathrm{PnP}$ fracturing might promote the axial fracture generation (stages 3 and 5 in Fig. 24). The use of single-entry (single-cluster) fracture sleeves with fracture ports minimizes this interference. Finally, $\mathrm{PnP}$ operations exhibit inflexibility in nonsequential treatment of stages. East et al. (2011), Soliman et al. (2010), Wellhoefer et al. (2014), and Yadali Jamaloei (2019b, c, d) outline the operational considerations, advantages, and disadvantages of using PnP methods. Some of these issues in PnP operations warranted developing interventionless completion systems for compartmentalized isolation

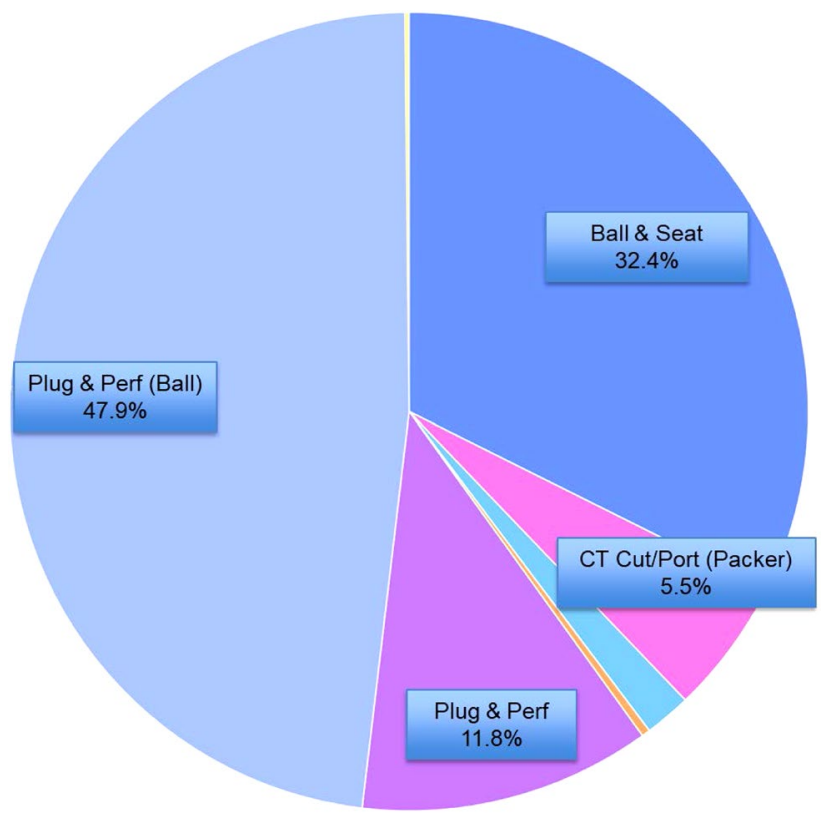

designs along the wellbore, and thus, a rationale in developing the ball-and-seat methods.

The ball-and-seat methods can be deployed with single-entry (similar to CT-activated sleeves) and multipleentry completions. The single-entry ball-and-seat methods (Fig. 25) rely on dropping sized balls from the surface to open the sleeves (these balls also provide progressive downstream isolation as the treatment is being pumped from the toe to the heel), which are preinstalled with a liner string. When these sleeves are not cemented in place, and hence, are used along with open-hole isolation packers, an external stress component is exerted on the wellbore by the external packer (risk of wellbore breakdown along its axis because of the higher risk of generation of axial fractures). This concept is shown in Fig. 26 (Roundtree et al. 2009). This is one of the risks that the ball-and-seat methods in the Montney might exhibit. These methods also place some limits on the maximum number of stages that can be placed in a wellbore (because of the activation balls and ball seats with graduated size against the geometry of the tubular), and thus, the risk of understimulation (as revealed in this review in Sect. 3) or uneven stimulation along the completed lateral, especially in liquid-rich areas of the Montney. Additionally, the treatment rate is often limited for the smaller-size activation balls utilized for the seats toward the wellbore toe. With progressively higher pumping rates, which can be used toward the heel, the erosion of the larger-sized-ball seats might hamper an effective sealing of the seat by the ball. Besides these operational and well performance issues, there are other geomechanical issues that might arise in open-hole completions (if sleeves are not cemented), which are beyond the 
Fig. 20 Comparison of well completion-type performance (normalized by completed lateral length and total fluid/ proppant placed) for Company F (Wells Group 7) based on treatment fluid, completion date, TVD, total fluid pumped, and total proppant placed
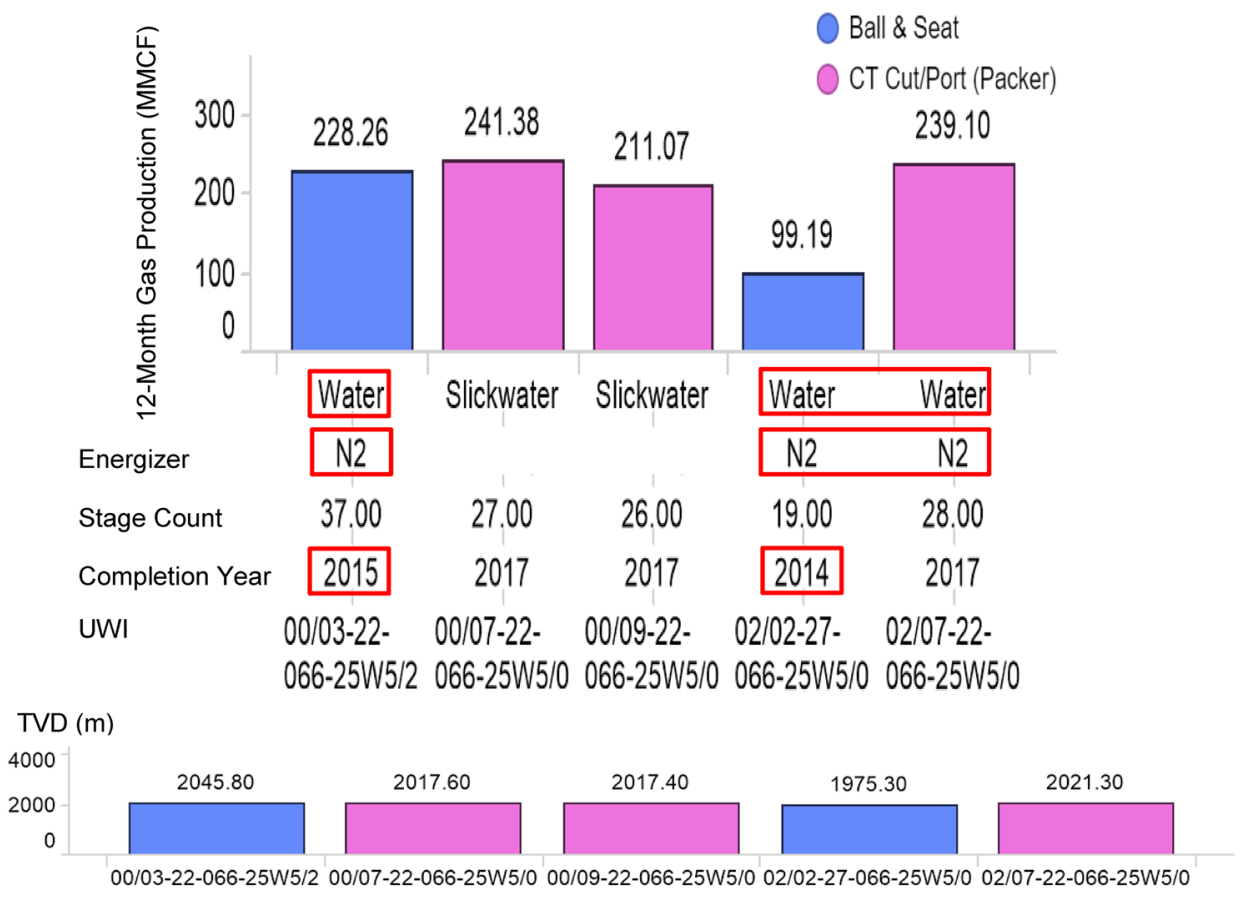

12-Month Gas Production Over Total Proppant Placed (MMCF/t)

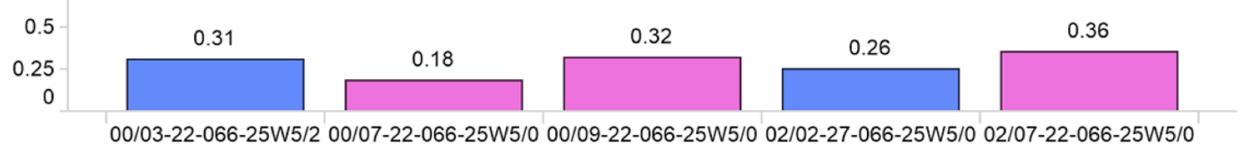

12-Month Gas Production Over Lateral Length (MBO/m)

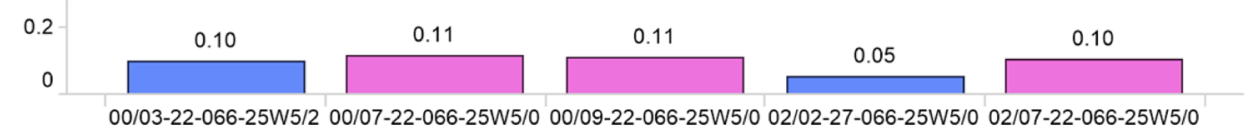

12-Month Gas Production Over Total Fluid Pumped $\left(\mathrm{MMCF} / \mathrm{m}^{3}\right)$

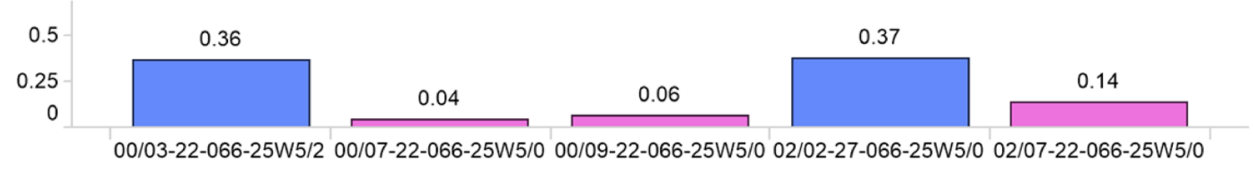

Total Fluid Pumped $\left(\mathrm{m}^{3}\right)$

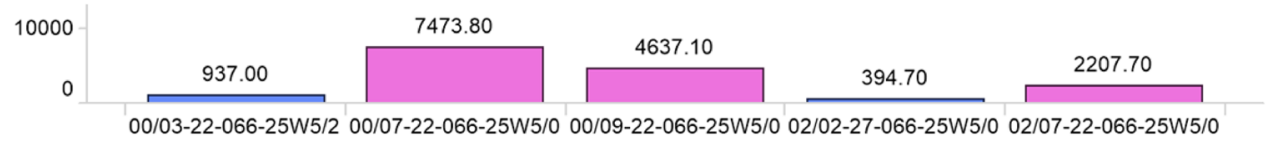

Total Proppant Placed (t)

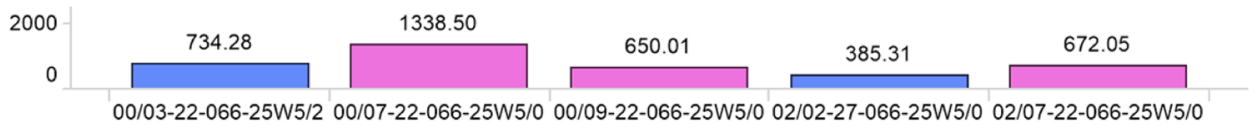

scope of this study. Daneshy (2011) and Wellhoefer et al. (2014) discuss the advantages and limitation of these completion methods in more details.

The conditions not amenable to CT-activated single-entry pinpoint fracturing (Fig. 27) should also be highlighted. Any possible casing cramping or deformation (e.g., in abnormally overpressured zones, cement integrity issues, and so forth) hampers an effective CT movement, and thus, an efficient deployment of any CT-activated single-entry pinpoint fracturing method. The deformation of casing has been observed 
Fig. 21 Comparison of well completion-type performance (normalized by completed lateral length and total fluid/ proppant placed) for Company F (Wells Group 3) based on treatment fluid, completion date, TVD, total fluid pumped, and total proppant placed
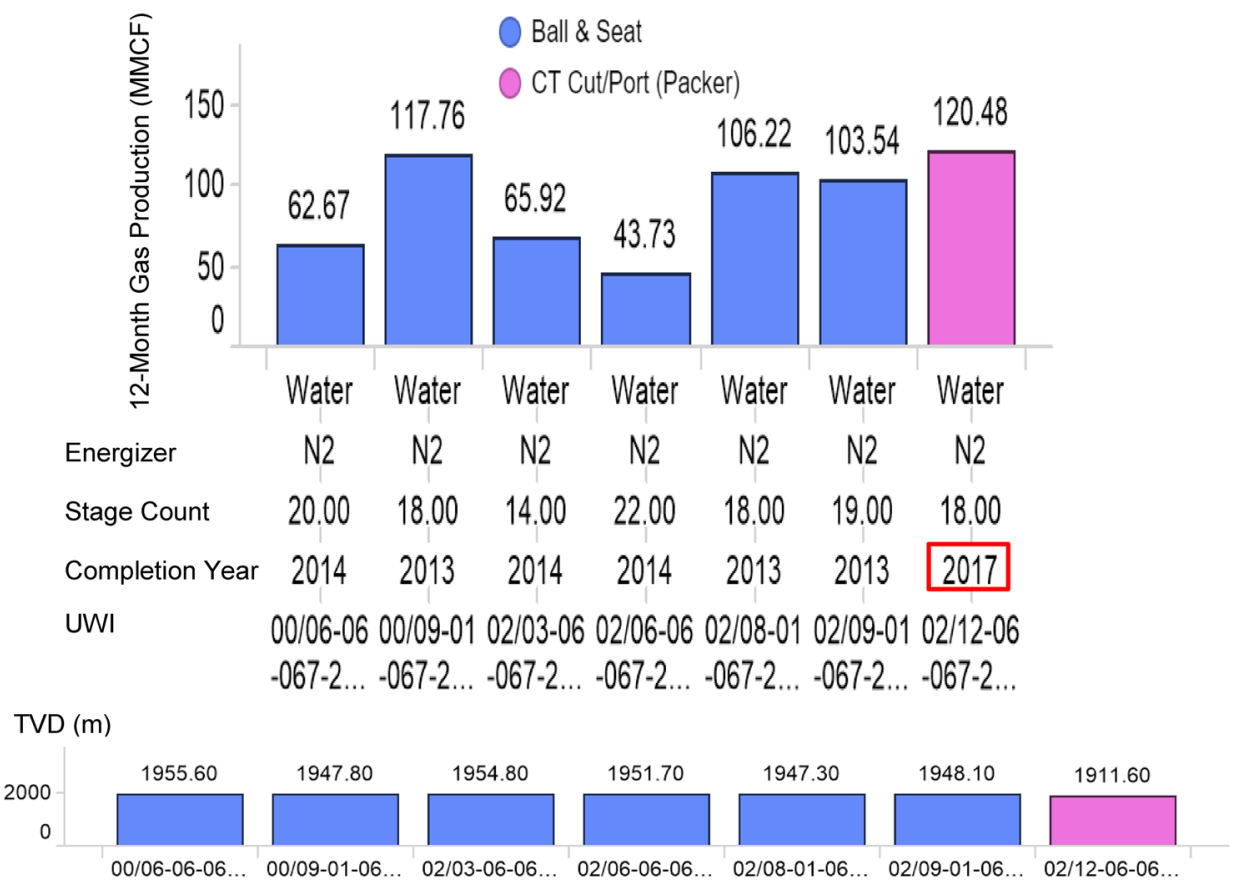

12-Month Gas Production Over Total Proppant Placed (MMCF/t)

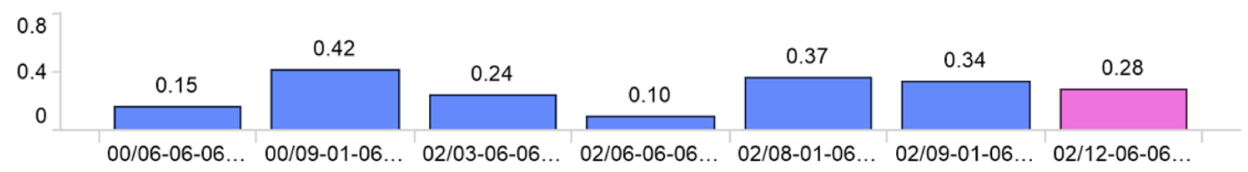

12-Month Gas Production Over Lateral Length ( $\mathrm{MBO} / \mathrm{m})$

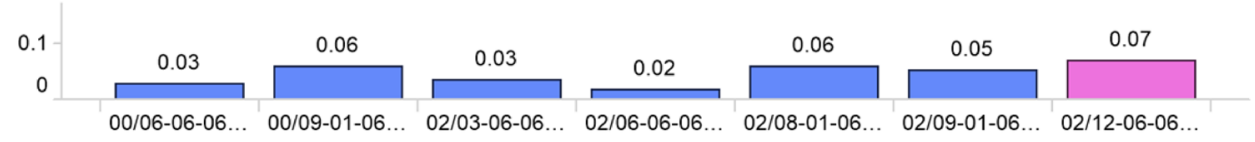

12-Month Gas Production Over Total Fluid Pumped (MMCF $/ \mathrm{m}^{3}$ )

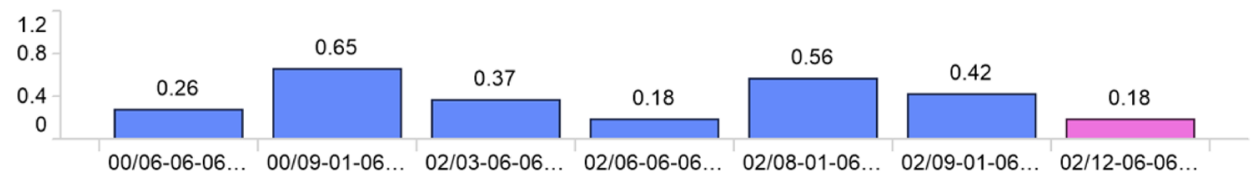

Total Fluid Pumped $\left(\mathrm{m}^{3}\right)$

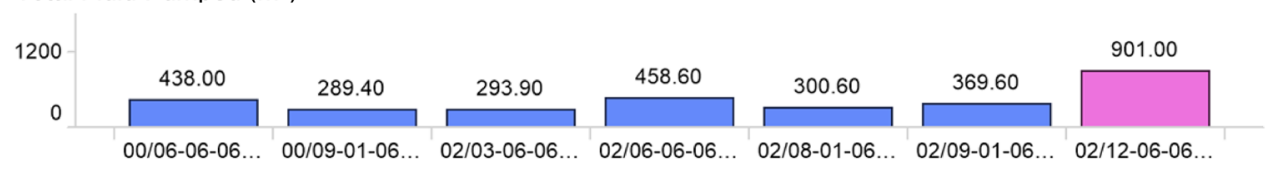

Total Proppant Placed (t)

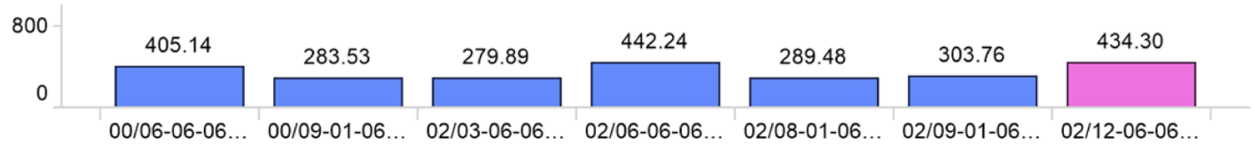

in some deeper areas of the Montney. Furthermore, simultaneous operation for fracturing multiple wells might not be as efficient using the CT-activated pinpoint fracturing, as compared with the PnP methods. The presence of abnormally high instantaneous shut-in pressures (ISIP) at the end of any fractured stage might potentially hamper an effective CT movement to the next stage because of the risk of damage to the CT string. In such a situation, the CT movement to the next stage should be delayed so the pressure inside the wellbore and the fracture dissipates further into the formation 
Fig. 22 Comparison of well completion-type performance (normalized by completed lateral length and total fluid/ proppant placed) for Company F (Wells Group 10) based on treatment fluid, completion date, TVD, total fluid pumped, and total proppant placed

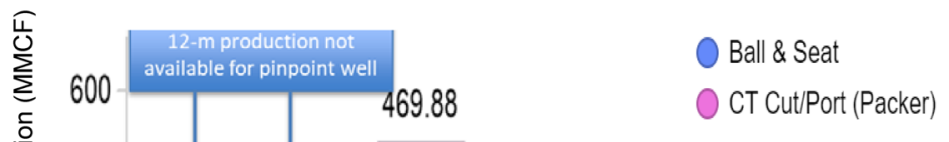

298.42

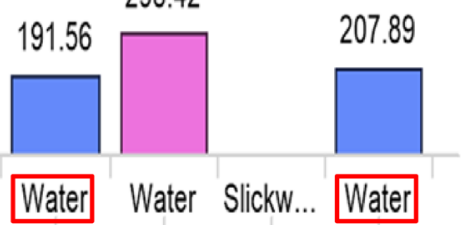

N2 $\quad$ N2

Energizer

$\begin{array}{llllllll}\text { Stage Count } & 47.00 & 43.00 & 24.00 & 16.00 & 25.00 & 43.00 & 16.00\end{array}$

$\begin{array}{llllllll}\text { Completion Year } & 2018 & 2018 & 2016 & 2013 & 2016 & 2018 & 2013\end{array}$

uWI $\quad 00 / 03-36$ 00//07-36 00/10-36 00/15-31 00/16-36 02/10-36 02/15-31 $-065-2 \ldots .-065-2 \ldots .-065-2 \ldots .-065-2 \ldots . .065-2 \ldots . .065-2 \ldots . .065-2 \ldots$

TVD (m)

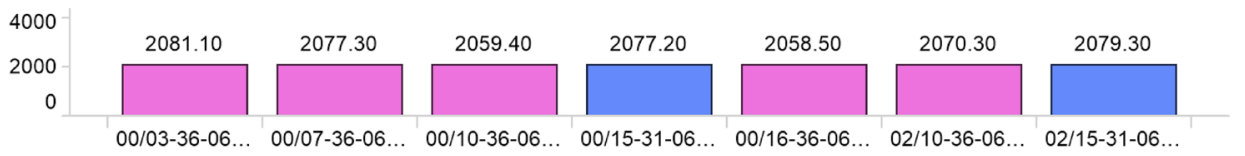

12-Month Gas Production Over Total Proppant Placed (MMCF/t)

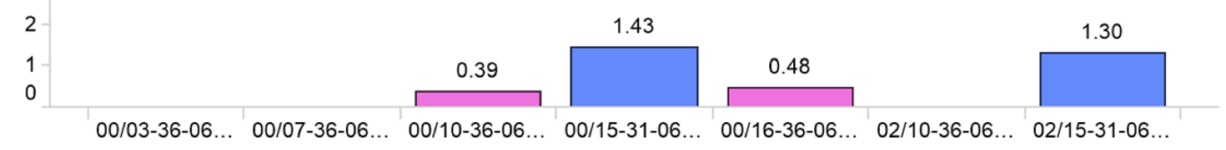

12-Month Gas Production Over Lateral Length (MBO/m)

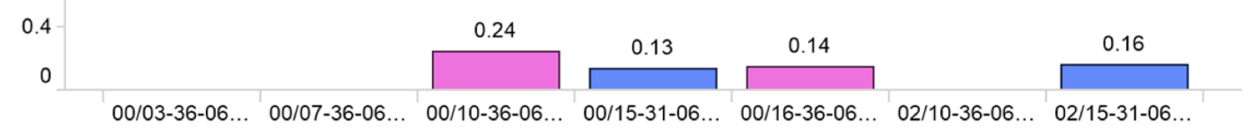

12-Month Gas Production Over Total Fluid Pumped (MMCF $/ \mathrm{m}^{3}$ )

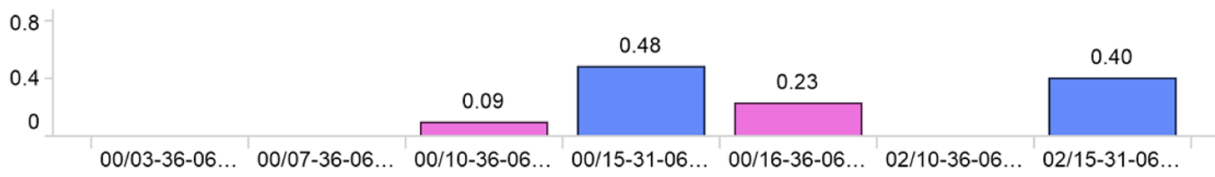

Total Fluid Pumped $\left(\mathrm{m}^{3}\right)$

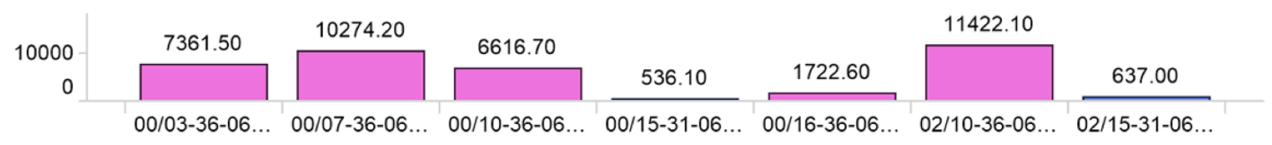

Total Proppant Placed ( $\mathrm{t}$ )

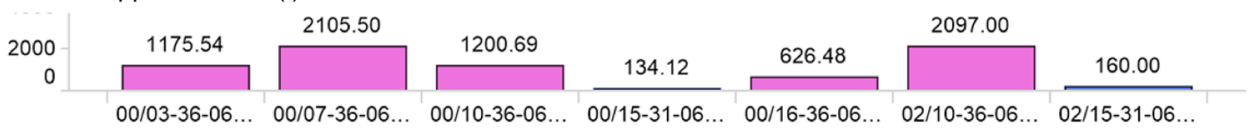

(fractures bleeding off). Should this occur frequently over the length of a wellbore, the cumulative completion time and costs might add up. Yadali Jamaloei (2020a, 2020b) discusses the advantages and challenges of using CT-activated single-entry pinpoint fracturing with multicycle closable sliding sleeves.
All in all, this clustering technique has shown how proper data structuring in disparate datasets with thousands of wells with significant variations in geological properties, fluid windows, completion type/design/fluid, regional depletion, and drawdown strategy permits a consistent well performance comparison across a play by 
Fig. 23 Plug-and-perforate $(\mathrm{PnP})$ fracturing method

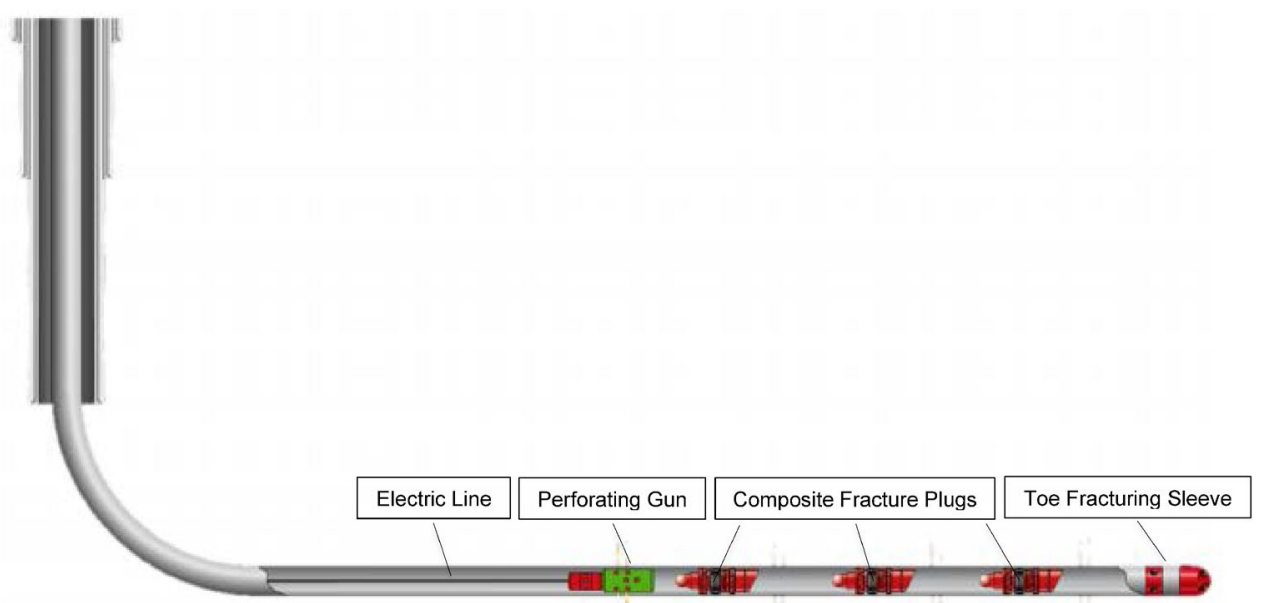

Fig. 24 The interference that exists between multiple clusters of perforations in the limited entry fracturing promotes axial fracture generation (stages 3 and 5). The use of single-entry (single-cluster) frac sleeves with frac ports minimizes this interference

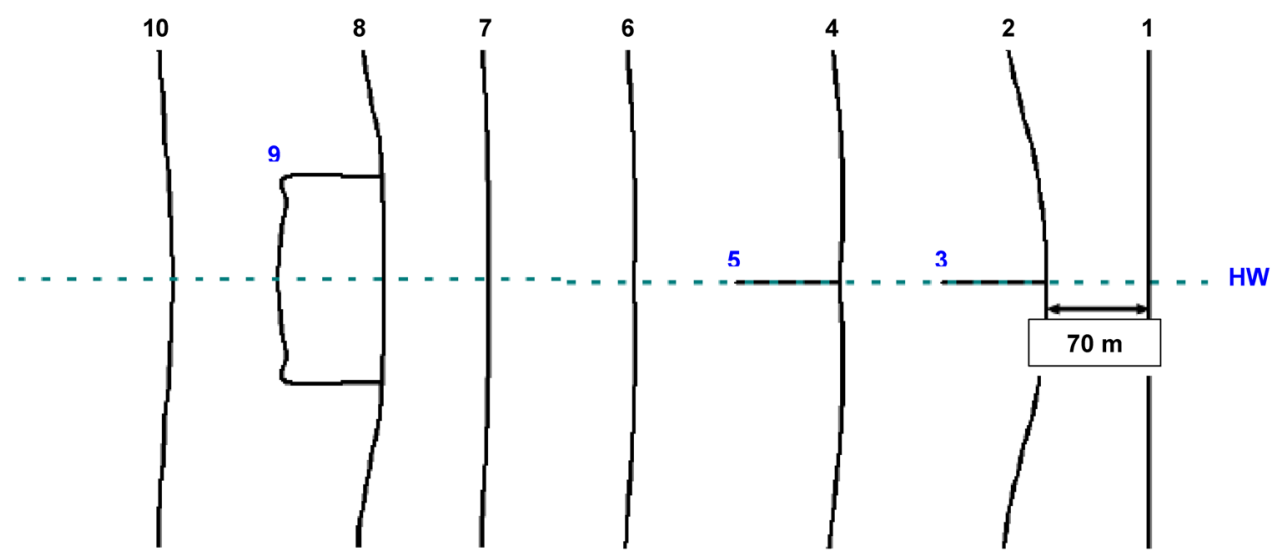

isolating the impact of any given parameter (e.g., completion types, fluids, depletion, etc.) that is deemed more crucial to completion design and field development planning.

\section{Conclusions}

- This work eliminates the limitations of previous studies by clustering the wells based on the completed lateral length, completion type/fluid/design/date, operator, and TVD. Moreover, it compares the performance of each well to that of its offsets with varying completion types but similar TVD, fluid window, drawdown strategy, and completion date/fluid.

- In each of the well groups considered across the entire Montney region, the performance of each well is compared only to that of its offsets with similar TVD and geological properties. Thus, the influence exerted by the physical and geological properties of the reservoir (e.g., in connection with the spread of the sweet spots) is minimized.
- The pinpoint wells outperform their ball-and-seat and PnP offsets, with similar TVD, completion date, and fluid.

- The ball-and-seat and PnP wells that outperform their offset pinpoint wells have either been completed one to four years earlier than pinpoint wells and/or used energized oil-based fluid, hybrid fluid, and energized slickwater versus slickwater used in the pinpoint offsets.

- The results highlight the significant, complex interplays between the type of fracturing method, design, and fluid, regional depletion, and reservoir properties in completion optimization, especially in formations with water-phase trapping issues.

- There is no single preferred or optimal completion method or fluid across the Montney play. Each one of the fracturing methods reviewed in this study exhibits some disadvantages. Ultimately, a combination of reservoir geomechanics/geology, costs, well performance, and operational/logistical considerations determines an appropriate completion method and fluid in each area of the Montney. 
Fig. 25 Fracturing sleeve ball activation process in ball-andseat method (Wellhoefer et al. 2014)

Fig. 26 Stress induced (vertical axis) by an external inflatable packer versus the distance from the wellbore. Using external packers creates some potential sites for the initiation of axial fractures near the wellbore, as it was shown by Roundtree et al. (2009)

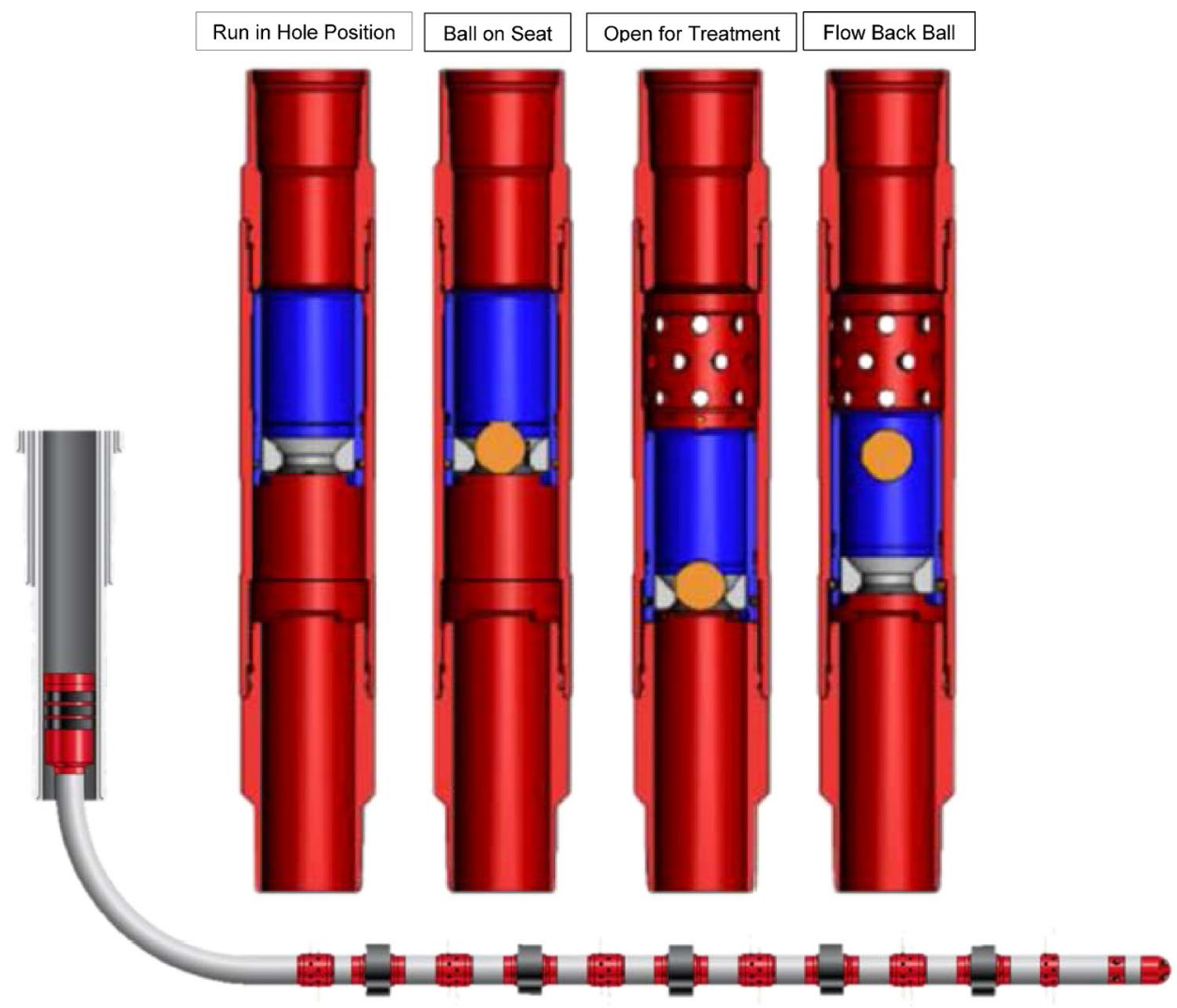

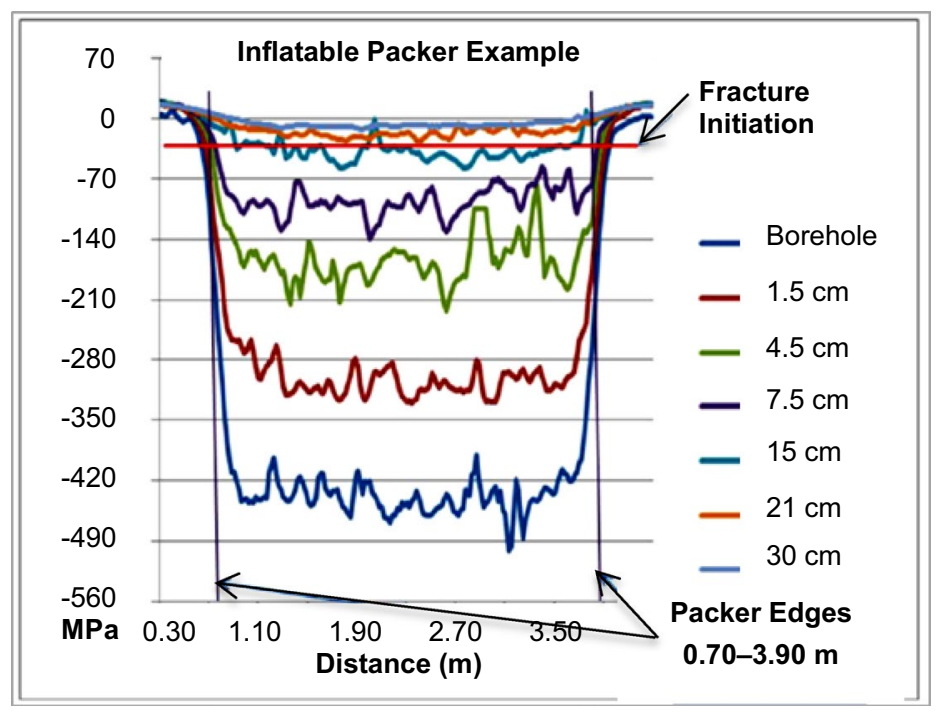




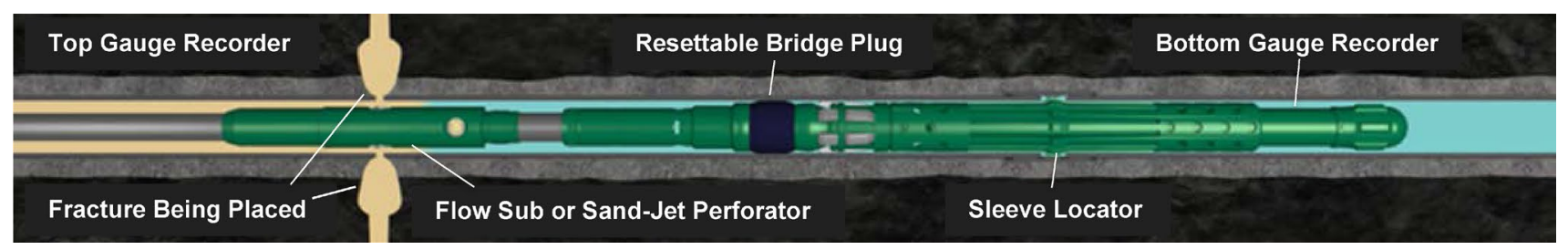

Fig. 27 The fracture pressure is applied (here down the annulus) to perform the fracturing. The coiled tubing serves as a dead leg for monitoring the pressure at the fracturing point to adjust pad size, sand

\section{Compliance with ethical standards}

Funding This study did not receive any funding from any internal or external resources.

Conflict of interest The corresponding author states that there is no conflict of interest; that is, the author has no known competing financial interests or personal relationships that could have appeared to influence the work reported in this paper.

Open Access This article is licensed under a Creative Commons Attribution 4.0 International License, which permits use, sharing, adaptation, distribution and reproduction in any medium or format, as long as you give appropriate credit to the original author(s) and the source, provide a link to the Creative Commons licence, and indicate if changes were made. The images or other third party material in this article are included in the article's Creative Commons licence, unless indicated otherwise in a credit line to the material. If material is not included in the article's Creative Commons licence and your intended use is not permitted by statutory regulation or exceeds the permitted use, you will need to obtain permission directly from the copyright holder. To view a copy of this licence, visit http://creativecommons.org/licenses/by/4.0/.

\section{References}

Al-Alwani M, Britt LK, Dunn-Norman S (2015) Data mining and statistical analysis of completions in an unconventional play: the canadian montney formation. Paper SPE-178586/ URTEC2154384-MS, Presented at the unconventional resources technology conference, 20-22 July, San Antonio, Texas, USA. Doi:https ://doi.org/10.15530/URTEC-2015-2154384

Barree RC (2016) Fracture conductivity and cleanup in GOHFER ${ }^{\circledR}$. Barree and Associates, Lakewood, Colorado

Daneshy AA (2011) Hydraulic fracturing of horizontal wells: issues and insights. Paper SPE-140134-MS, Presented at the SPE hydraulic fracturing technology conference, 24-26 January, The Woodlands, Texas, USA. doi:https://doi.org/10.2118/140134-MS

East L, Soliman M, Augustine J (2011) Methods for enhancing far-field fracture complexity. SPE Prod Oper 26(3):291-303

Groulx B, Gouveia J, Chenery D (2017) Multivariate analysis using advanced probabilistic techniques for completion design optimization. Paper SPE-185077, Presented at the SPE Unconventional resources conference, 15-16 February, Calgary, Alberta, Canada. Doi:https://doi.org/10.2118/185077-MS

Kong B, Wang S, Chen S (2017) Minimize formation damage in watersensitive montney formation with energized fracturing fluid. SPE Reserv Eval Eng 20(03):562. https://doi.org/10.2118/179019-PA concentration, fluid viscosity, and pump pressure in real time. After the last stage, the multi-set bridge plug is unset, the BHA is retrieved, and the full-open wellbore is ready for production

Mohammed OQ, Britt LK, Dunn-Norman S (2016) evaluating multiple fractured cased hole completion performance for gas wells in the upper and the lower montney formation, Canada. Paper SPE-181809, Presented at the SPE Asia Pacific hydraulic fracturing conference, 24-26 August, Beijing, China. Doi:https://doi. org/10.2118/181809-MS

Okouma MV, Nair NG, Miller M, Vitthal S (2012) Playwide well performance analysis in montney siltstone. Paper SPE-162843, Presented at the SPE Canadian Unconventional Resources Conference, 30 October-1 November, Calgary, Alberta, Canada. Doi: https://doi.org/10.2118/162843-MS

Reimer J (2015) Hydrocarbon recovery optimization in the montney formation: framing key challenges relating to shale gas development for industry and external stakeholders. Canadian Society of Unconventional Resources (CSUR) Technical Meeting, Feb. 11, Calgary, Alberta, Canada

Reynolds MM, Bachman RC, Peters WE (2014) A comparison of the effectiveness of various fracture fluid systems used in multistage fractured horizontal wells: montney formation, unconventional gas. Paper SPE-168632, Presented at the SPE hydraulic fracturing technology conference, 4-6 February, The Woodlands, Texas, USA. Doi:https://doi.org/10.2118/168632-MS

Reynolds M, Bachman R, Buendia J, Peters W (2015) The full montney-a critical review of well performance by production analysis of over 2000 montney multi-stage fractured horizontal gas wells. Paper SPE-175948, SPE/CSUR Unconventional Resources Conference, 20-22 October, Calgary, Alberta, Canada.Doi: https ://doi.org/10.2118/175948-MS

Roundtree R, Barree RD, Eberhard, MJ (2009) Horizontal, nearwellbore stress effects on fracture initiation. Paper SPE 123589, Presented at the SPE rocky mountain petroleum technology conference, Denver, Colorado, USA

Seifert M, Geol P, Lenko M, Eng P, Lee J (2015) Optimizing completions within the montney resource play. Paper SPE-178490/ URTEC-2015-2139640, Presented at the Unconventional Resources Technology Conference, 20-22 July, San Antonio, Texas, USA. Doi: https://doi.org/10.15530/URTEC-2015-21396 40

Soliman MY, East LE, Adams DL (2008) Geomechanics aspects of multiple fracturing of horizontal and vertical wells. SPE Drill Completion 23(03):217-228

Soliman M, East L, Augustine J, (2010) Fracturing design aimed at enhancing fracture complexity. Paper SPE-130043, Presented at the SPE EUROPEC/EAGE annual conference and exhibition, Barcelona, Spain

Taylor RS, Fyten G, Romanson R, McIntosh G, Litun R, Munn D, Hoch O (2010) Montney fracturing-fluid considerations. J Can Petrol Tech 49(12):28-36. https://doi.org/10.2118/143113-PA

Voneiff G, Sadeghi S, Bastian P, Wolters B, Jochen J, Chow B, Gatens M (2013) A well performance model based on multivariate 
analysis of completion and production data from horizontal wells in the montney formation in British Columbia. Paper SPE167154, Presented at the SPE unconventional resources conference Canada, 5-7 November, Calgary, Alberta, Canada. Doi: https ://doi.org/10.2118/167154-MS

Voneiff G, Sadeghi S, Bastian P, Wolters B, Jochen J, Chow B, Gatens M (2014) Probabilistic forecasting of horizontal well performance in unconventional reservoirs using publicly-available completion data. Paper SPE-168978, Presented at the SPE Unconventional resources conference, 1-3 April, The Woodlands, Texas, USA. Doi: https://doi.org/10.2118/168978-MS

Wang S, Chen S (2016) Evaluation and prediction of hydraulic fractured well performance in montney formations using a data-driven approach. Paper SPE-180416, Presented at the SPE Western Regional Meeting, 23-26 May, Anchorage, Alaska, USA. Doi: https://doi.org/10.2118/180416-MS

Wellhoefer BJ, Eis A, Gullickson GW (2014) Does multi-entry multistage fracturing sleeve system improve production in bakken shale wells over other completion methods? Paper SPE-171629, Presented at the SPE/CSUR unconventional resources conferenceCanada, 30 September-2 October, Calgary, Alberta, Canada. Doi: https://doi.org/10.2118/171629-MS

Yadali Jamaloei B (2019a) Geomechanical impacts of the in-situ stresses in the application of out-of-sequence pinpoint fracturing. Paper SPE-198120, Presented at the Kuwait Oil and Gas Conference and Show, Mishref, Kuwait. Doi: https://doi. org/10.2118/198120-MS

Yadali Jamaloei B (2019b) Identifying well treatment candidates and strategies for enhancing hydraulic fractures system complexity. Paper SPE-195212, Presented at the SPE Oklahoma City Oil and Gas Symposium, Oklahoma City, Oklahoma, USA. Doi: https:// doi.org/10.2118/195212-MS
Yadali Jamaloei B (2019c) Lessons learned from history-matching the first out-of-sequence fracturing field test in North America. Paper SPE-197227, Presented at the Abu Dhabi International Petroleum Exhibition and Conference (ADIPEC), Abu Dhabi, UAE. Doi: https://doi.org/10.2118/197227-MS

Yadali Jamaloei B (2019d) Preliminary considerations on the application of out-of-sequence multi-stage pinpoint fracturing. Paper SPE-196310, Presented at the SPE/IATMI Asia Pacific Oil and Gas Conference and Exhibition, Bali, Indonesia. Doi: https://doi. org/10.2118/196310-MS

Yadali Jamaloei B (2019e) A review of preliminary out-of-sequence pinpoint fracturing field trials in North America. Paper SPE198023, Presented at the Kuwait Oil and Gas Conference and Show, Mishref, Kuwait. Doi: https://doi.org/10.2118/198023-MS

Yadali Jamaloei B (2020a) The first out-of-sequence fracturing field test in North America: key learnings from operation, petrophysical analysis, fracture modeling, and production history-matching. SPE Prod Oper. https://doi.org/10.2118/197227-PA

Yadali Jamaloei B (2020b) A coupled flow-geomechanical modeling of out-of-sequence fracturing using a dual-lattice implementation of synthetic rock mass approach. SPE Prod Oper. https://doi. org/10.2118/203844-PA

Yadali Jamaloei B (2020c) Practical considerations in alternate fracturing with shift-fracture-close operation: learnings from geomechanical modeling and downhole diagnostics. SPE Drill Completion. https://doi.org/10.2118/204211-PA

Publisher's Note Springer Nature remains neutral with regard to jurisdictional claims in published maps and institutional affiliations. 